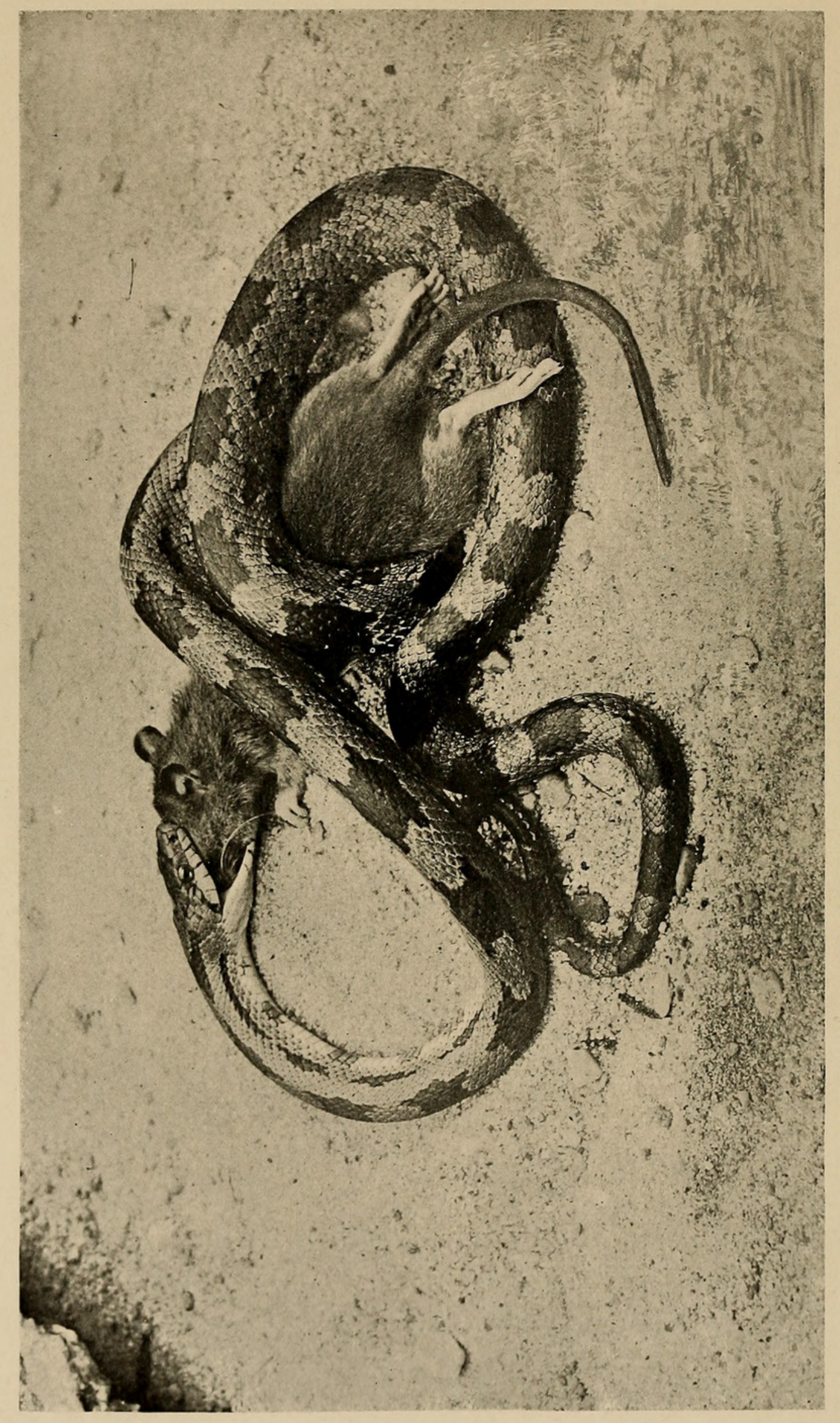

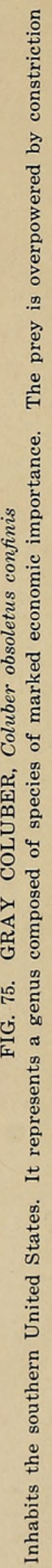




\title{
THE FEEDING HABITS OF SERPENTS
}

\author{
By Raymond L. Ditmars.
}

\section{INTRODUCTION}

From a series of observations embracing a period of many years the writer has drawn the conclusions and prepared the notes herewith presented. He has been particularly fortunate in the possession of elaborate material in pursuing his studies of a zoological specialty. Ten years prior and up to the time of assuming charge of the reptiles in the Zoological Park, the writer maintained a large collection of living serpents, with which his investigations permitted the observation of individual examples. Such work is of great value, yet largely impossible in the care of a great collection like that we have installed in our Reptile House. However, in the latter comes the ability to maintain a thoroughly representative series of subjects with the consequent possibility of comparison of habits. All phases of serpent life relating to habits and structure have been represented in the collection of the New York Zoological Society. Yet this very elaboration of exhibition, so instructive to our visitors, is detrimental to the condition of the reptiles, as it renders individual attention impossible and thereby shortens the life of the greater number of specimens.

Quite different from other vertebrates, the feeding of snakes is so influenced by temperature, light, the nervous condition of the reptile, or the slightest ill-health, that any of these causes slightly deviating from the normal will result in an abrupt cessation of feeding. It is possible to produce normal conditions and induce steady feeding with but a comparatively small proportion of snakes,-about half of the total number of species that it is possible to obtain for exhibition. Some feed irregularly, and their lives as captives are short. There are representatives of a few species that never have been induced to feed in captivity. The latter are mostly poisonous snakes. 
The development of the nervous organization appears to play an important part in the feeding habits. The most highly specialized types, the viperine poisonous snakes, possess a highly sensitive nervous organization and for the most part are short-lived under observation. It is among these reptiles that we note mystifying habits, and among representatives of some of the species, an utter disinclination to feed. Though provided with deadly, venom-conducting fangs, and an amazing dexterity in the use of these weapons both in obtaining food and in defense, these formidable creatures invariably remain more timid than their innocuous allies which become readily accustomed to change of environment.

In preparing this resume of a considerable series of genera and species, the writer hopes that it may contribute something toward a solution of some of the problems of evolution and relationship which fall to the lot of the systematist.

While considering the feeding habits of an extensive order like the Ophidia, some of the members of which cling to ancestral characteristics, while others have become highly specialized, a first impression might lead the novice to presuppose the existence of a great variety of foods. This is not actually the case. The food of serpents is considerably less elaborate than of the Order that embraces the ancestral forms of the snakes, the lizards. The point of primary importance to be noted is the fact that serpents are carnivorous and a few insectivorous; no species of snake is known to be herbivorous. Among the lizards the herbivorous species exist in large number. This is also the case with the latter Order in regard to insectivorous species. There are few species of insectivorous serpents, however, and the habit is noted as occurring arbitrarily among both small species of directly ancient lineage and others which are markedly specialized.

The great percentage of serpents feed upon forms of vertebrate life. A large number feed exclusively upon mammals and birds, and a like proportion subsist entirely upon cold-blooded vertebrates. There are many species with feeding habits not so well defined and which feed upon either mammals, birds, reptiles or batrachians; these we will term omni-carnivorous species. Many species are cannibalistic and a few feed altogether upon eggs.

In the development of serpent life, even among the crudest forms, we immediately note the great modification of the structure of the 


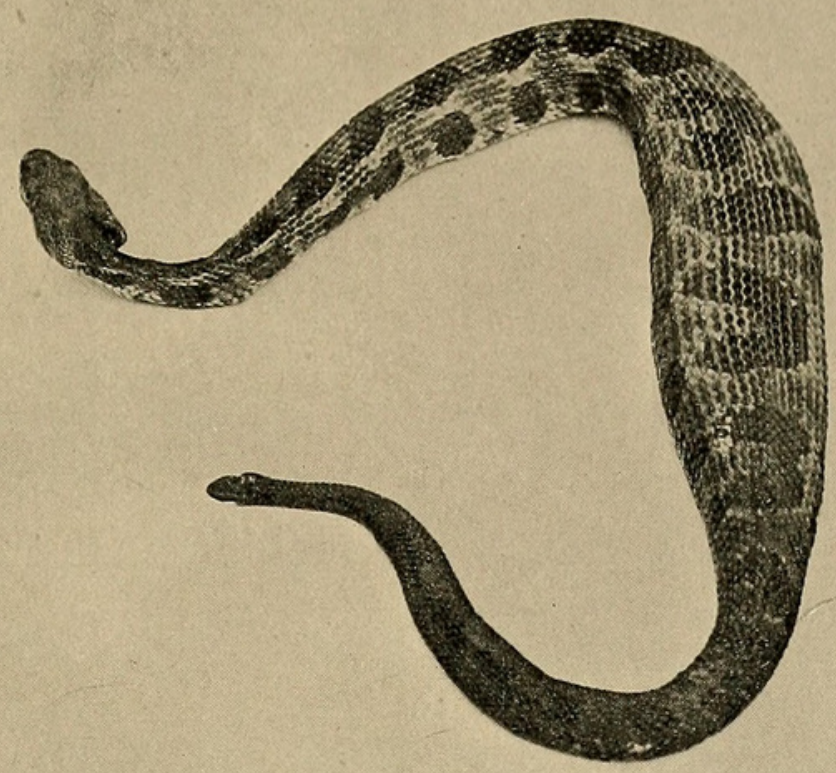

FIG. 76. RATTLESNAKE DIGESTING A MOUSE

The great elasticity of the swallowing mechanism enables the serpent to consume, without mastication, prey that is four to six times the diameter of the reptile's neck

FIG. 77. CORN SNAKE, Coluber guttatus

A typical constrictor. Inhabits the southern United States 
jaw bones, this pointing to carnivorous habits. Among the highly specialized types of the later groups, this modification has developed into a structure that enables the serpent to easily manipulate its living prey, without the use of the bodily coils. A number of snakes thus swallow their prey alive, without resorting to constriction or other means of overpowering it.

Though the snakes are largely carnivorous, the methods of hunting and overpowering the prey differ widely among the members of the various families and genera.

\section{Part I.-Methods of Feeding}

Snakes practice various methods in killing their prey, but these widely different habits are displayed as unvarying characteristics among the members of genera and families. In some families, such as the cosmopolitan Colubridae with its several subfamilies, there exists every method of subduing the prey that is to be noted among snakes. Among the members of other families, the manipulation of the freshly captured prey is usually of a respectively unvarying character. Such families may represent the older types or those of marked specialization. Accordingly, from the viewpoint of their feeding habits, the serpents may be crudely divided into several fairly well-defined groups, but owing to the variability of habits that exists within occasional families, these groups are constructed merely in systematizing the present article, not in accordance with zoological classification.

The suggested groups may be outlined as follows:

\section{NON-VENOMOUS}

Constricting species: Serpents of all sizes that kill their prey by coiling about it and squeezing it to death. Members of the Boidae and Colubridae.

Semi-Constrictors: Species that swallow the living prey, but subdue it by holding within a single coil or pressing it firmly against the ground by a fold of the body while deglutition 
proceeds. Typical representatives are Colubrine snakes, Spilotes, Zamenis and allied genera.

Non-Constrictors: Serpents that swallow the living prey without effort to subdue it by bodily manipulation. A great number of such species are characterized by their possession of enlarged posterior teeth to permit a firmer hold of the quarry. Members of numerous Colubrine genera: Tropidonotus, Eutaenia and Heterodon are typical in the exhibition of this habit.

\section{VENOMOUS}

Among the poisonous snakes, we consider three types, viz.: the members of the Opisthoglypha and the Proteroglypha of the Colubridae, and the long-fanged members of the Viperidae. Two welldefined methods of killing the prey may be noted:

a. The snake seizes the quarry and by a gripping movement of the jaws imbeds the fangs. The bitten animal is thus held until dead, when deglutition begins. A few species are constrictors, but possess little bodily power. These habits are typical of the venomous Colubridae, viz., the members of the subfamilies, Homalopsinae, Dipsadomorphinae, Hydrophiinae and Elapinae. The shorter-fanged members of the Viperidae feed in similar fashion, particularly those species that feed upon birds, lizards or batrachians.

$b$. Serpents that stab their prey and immediately release it, awaiting its rapid death by poisoning. This habit appears to be confined to the long-fanged members of the Viperidae. Typical genera are Crotalus and Bitis. While this is an almost invariable habit among captive examples of the genera, it must also be understood that such reptiles are excessively nervous and their feeding when wild-particularly in the treatment of smaller prey-may be similar to group " $a$ ".

By this summary we may note the characteristic feeding traits of serpents. Considering these from the standpoint of zoological arrangement of families, we observe little of significance as regards classification, except among the highly specialized forms which have acquired their remarkable venom-conducting teeth and deadly poison. In the process of evolution away from the lacertilian form, the snakes have acquired, with the elongation of their limbless bodies, a characteristic which appears to be unique among the Ophidia, when applied to the killing of the prey. This is constriction, a power which the writer has noted among lizards, but apparently put to no specific use. When handled, the worm-like lizards of the Amphisbænidae 


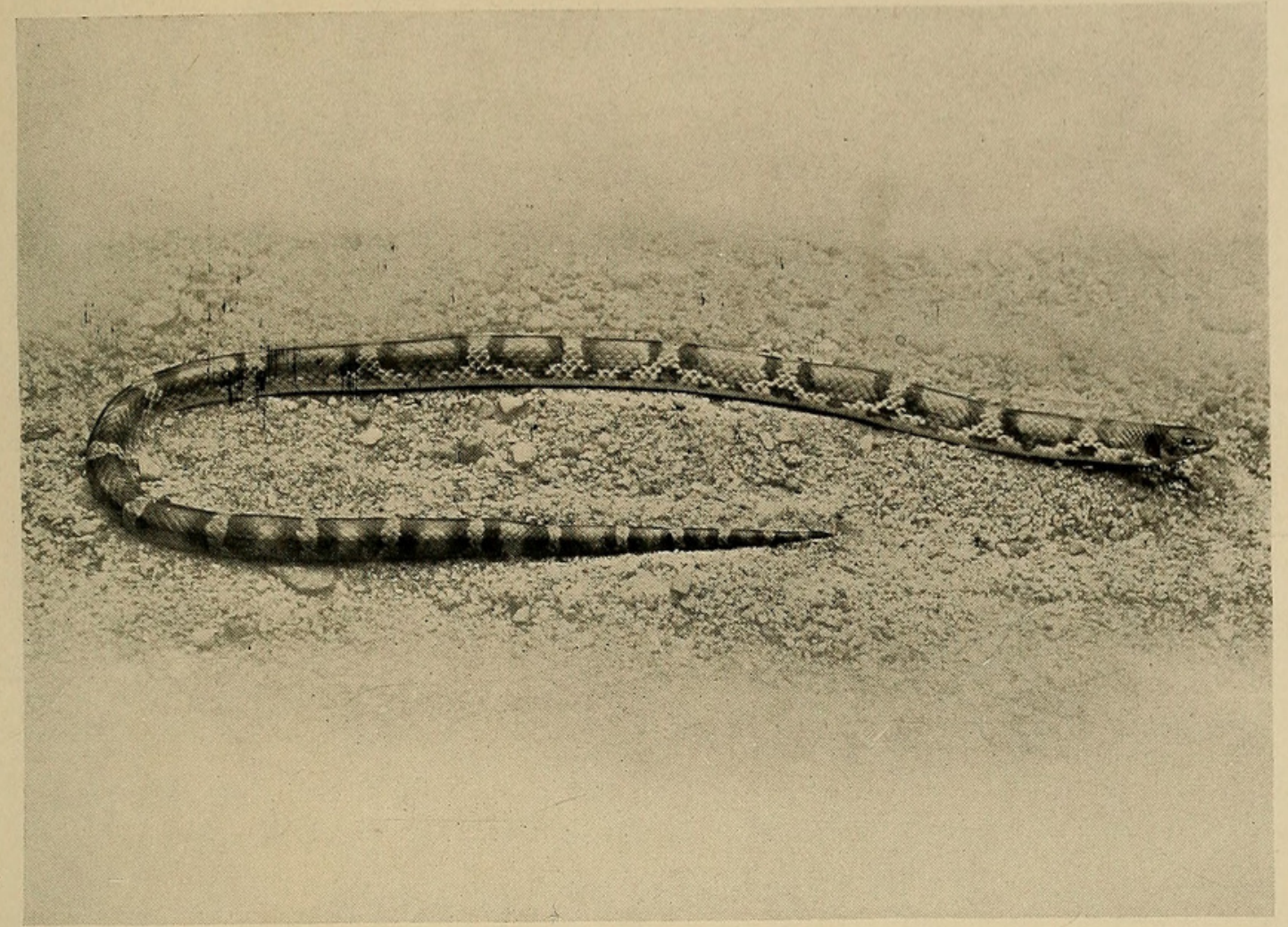

FIG. 78. SCARLET SNAKE, Cemophora coccinea

A degenerating type of the constricting serpent. Inhabits the Southern United States

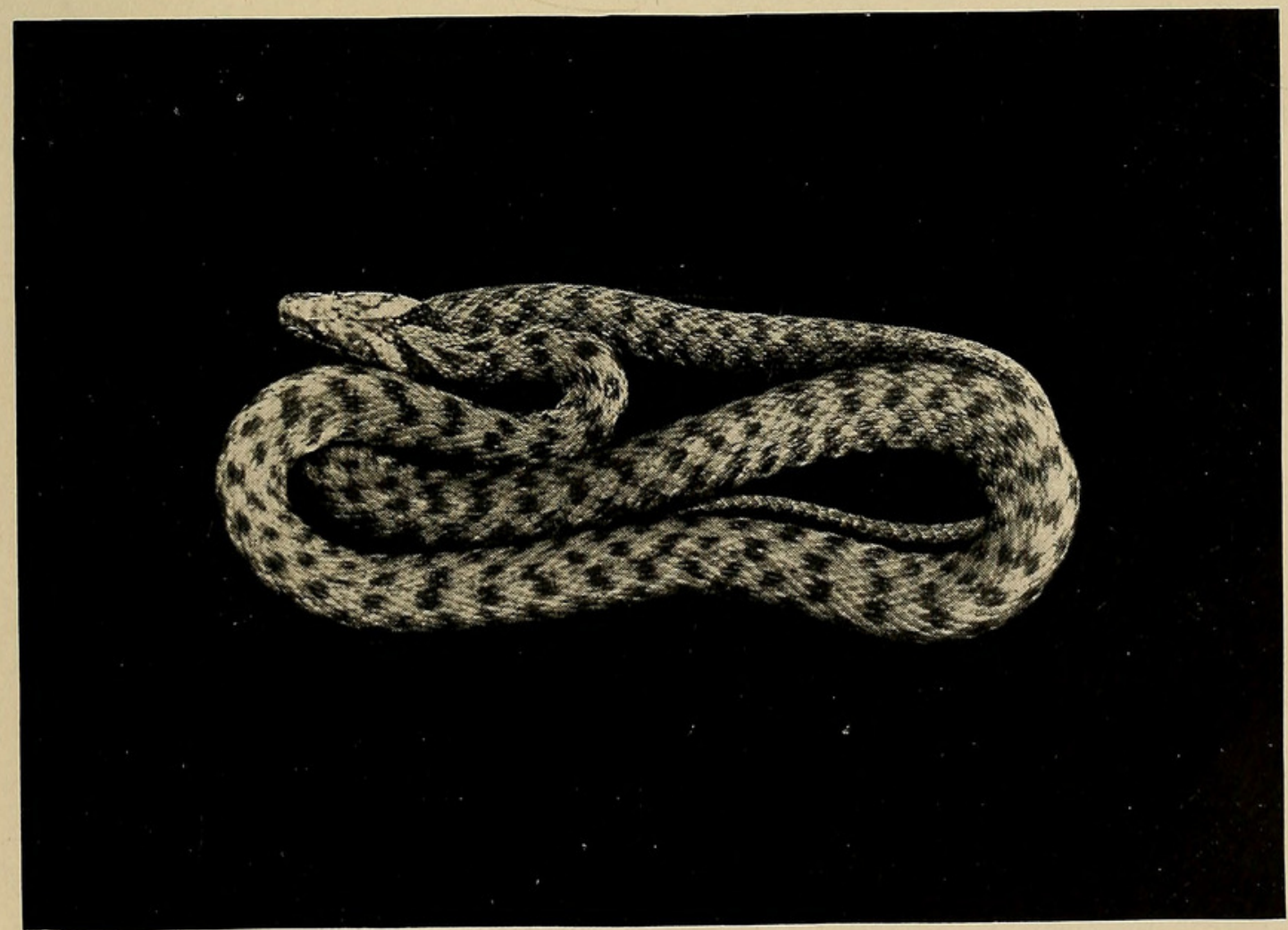

FIG. 79. WATER SNAKE, Tropidonotus tessellatus

The manipulation of the prey is by the jaws only. Snakes of this kind lack the power of constriction. Inhabits Europe 
exhibit power of constriction, and this is also to be noted among the crude and lowly serpents of ancient lineage, such as the Typhlopidae and Glauconiidae, but as all of these creatures are mainly insectivorous the power seems of no practical value. Constriction, as an efficient and unvarying method of killing the prey has apparently originated among the members of the Boidae, the ancient lineage of which serpents is evident by the presence of rudimentary hind limbs. During the process of specialization it has been retained by many members of the Colubridae, particularly those that feed upon warm blooded prey, and curiously enough a strong indication of it here and there appears among highly specialized forms, with well developed fangs. Intermediate traits have already been noted among the Colubrine semi-constrictors and those species which swallow the prey alive.

It is of interest in continuing this preliminary resume to note the relationship of food to the methods of feeding. The following table will concisely outline such observations:

\section{NON-VENOMOUS}

Constrictors*: Series $a$. Species that feed only upon warmblooded prey-mammals and birds. The greater number of the species of the Boidae. Many genera of the Colubridaeof which the members of Coluber are typical examples.

Series $b$. Species that feed upon warm and cold-bloo jed prey. These snakes devour mammals, birds and other reptiles, though few or none feed upon batrachians. Members of the Boidae and Colubridae.

Semi-Constrictors: Omni-carnivorous serpents feeding largely upon mammals and birds, but also reptiles and batrachians. Principally Colubrine snakes.

Non-Constrictors: The great majority of these species devour cold-blooded creatures-other reptiles, batrachians, fishes and insects. A large number of Colubrine genera come under

*The greater percentage of the food of constricting species consists of warm-blooded animals. 
this head, also the members of insectivorous families, the Typhlopidae and Glauconiidae.

\section{VENOMOUS}

This group embraces several types of feeders, thus:

a. Species that retain their hold after biting. b. Species that "strike" and release the prey.
Fish eaters.

$\left\{\begin{array}{l}\text { Lizard eaters. } \\ \text { Lizard \& bird eaters. } \\ \text { Omni-carnivorous. }\end{array}\right.$

Fish only.

$\left\{\begin{array}{l}\text { Mammals } \\ \text { Cannibalistic } \\ \text { Omni-carnivorous }\end{array}\right.$

Omni-carnivorous Viperidae

The highly specialized, long-fanged members of the Viperidae appear to feed largely upon mammals
Homalopsinae

Dipsadormorphince

Hydrophiinae

Elapirae

“

“6

After an outline of the feeding habits of serpents, it is well to review the more characteristic traits, means of hunting and stalking the prey, and the economic importance of certain species.

While the diminutive Worm Snake (Glauconia) of the South American tropics lies in a great ant-hill, where its burnished scalation protects it from the bites of the insects as it feeds upon their larvæ, the huge Boa or the Anaconda, lurks in the jungle growth along river banks on the watch for a passing peccary, capybara or agouti. When the prey is within reach, the neck is drawn into an S-shaped loop, preparatory to striking. It is the habit of these big snakes to lurk near the runways of various mammals, that they may thus capture them on their way to water or in passing from one feeding ground to another. The snake relies upon grasping the animal as it passes within striking distance. It is not unusual, however, if the illfated creature wanders by out of the striking zone, for the serpent to pursue. The movements of even the largest constrictors when stalking their prey are remarkably quick and stealthy. Such movements are seldom or never displayed by the big snakes unless prompted 


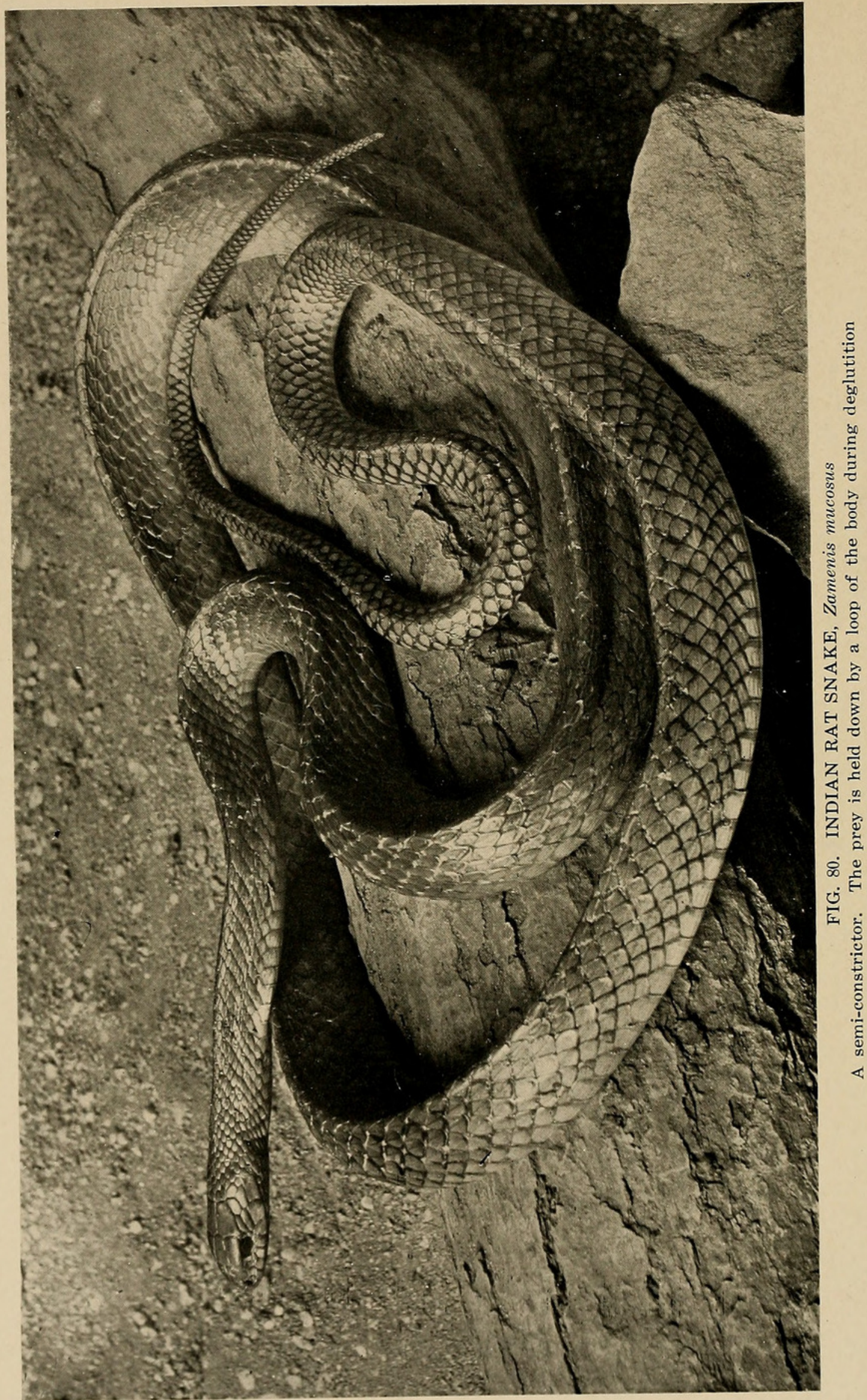


by appetite. With the prey within striking distance, there is a lunge of the head, the long recurved teeth take firm hold and the reptile's body is literally hurled about the victim, until it is covered with the constricting coils. The process of enveloping the quarry with the powerful folds is wonderfully dextrous among the large serpents. It exceeds in speed that of the smaller, colubrine serpents, which are proportionately more active in pursuit. In the feeding of a twentyfoot Python reticulatus involving a vigorous forty-pound pig, the writer noted on several occasions, with a stop watch, that the time consumed from the initial "strike" of the serpent's head, through the dashing of the coils about it and the beginning of actual constriction, to be within two seconds. The snake apparently aims to seize the animal anywhere and the dash to constrict it is to save the reptile injury. Death usually takes place within a minute's time, but during the animal's struggles the reptile, not infrequently, is severely bitten; though the only heed to the injury is to constrict more vigorously or bring another coil to bear. The writer has observed many of the smaller constricting snakes badly bitten by rats, and has examined freshly-caught specimens with severe scars.

The habits described in the preceding paragraph are generally typical of the constricting serpents. Their actions in subduing the prey are as characteristic as the injection of a deadly virus by serpents with fangs. Between the constrictors and the poisonous snakes, lie the groups of less pronounced feeding habits. The types we have called the semi-constrictors endeavor to subdue the struggles of the prey, by pressing the animal against the ground with a fold of the body while deglutition is proceeding. Snakes of this type feed upon comparatively small prey. Many of them are rodent-eaters; all are swift of gait and hunt openly, and when seizing small creatures possessing sharp teeth that might be used in vigorous defense, the reptile displays extreme caution in manipulating the animal with its jaws so as to place it at a disadvantage. By a lateral, pulling movement of the jawbones, these snakes endeavor to overpower their prey in the same fashion as the constrictors, by literally squeezing it to death.

Among those innocuous snakes which have been designated as non-constrictors, we note several characteristics in feeding, which point to radiating phases of specialization. The writer endeavors to point out these characteristics owing to the feeding habits of serpents being of particular interest in possibly tracing their develop- 
ment and relationship. It is understood that snakes subsist upon prey of great proportionate size, power and in possession of liberal means of defence. Yet these limbless reptiles, aside from the constricting habits of some and the poison-injecting teeth of others, depend absolutely upon the manipulation of the jawbones in the handling, possibly subjugation of the proportionately heavy quarry. Constriction was apparently the oldest type of subjugation, but changes in the dentition among various groups, influenced by the extension of distribution and change of food, brought about new methods of killing the object of food. Among the non-venomous members of the Colubridae that indicate no inclination to constrict, the structure of the teeth is in direct relationship to the habits. Thus the frog and fish-eating species have enlarged posterior teeth to quickly pierce and firmly grip the struggling victim. Snakes of this type evince an unique habit against the defensive actions of frogs and toads in greatly puffing up their bodies to prevent being swallowed. With repeated grippings of the enlarged posterior teeth, the serpent pierces the victim's air cavities thusfrustrating and overpowering it. With these snakes the dilatability of the swallowing structure and the agility of deglutition are markedly developed. The cosmopolitan genus Tropidonotus (Water Snakes) and the American genus Eutrnia (Striped Snakes) exhibit uniformly typical species of the habits described. With the North American "Adders," (Heterodon), we observe greater development of the dentition in utilization of these traits. In the upper jaw is a pair of posterior fang-like teeth that exhibit faint traces of an anterior groove when microscopically examined. Such development may point to the future elaboration of these greatly enlarged teeth into grooved, venom-conducting fangs, of similar structure to those of the Opisthoglypha. Similar grooved teeth are to be noted among other Colubrine snakes, apparent with some to a very faint degree.

Among the non-constricting Colubrine serpents the egg-eating Dasypeltis scabra, of Africa, stands as another type of radiating specialization in the manipulation of the food. Here, a weak-bodied creature is able to swallow an egg three times the diameter of the thickest part of the reptile's body. The jaws have become almost destitute of teeth, but the presence of a few posteriorly situated ones, provide the power for the jaw bones to alternately grip and engulf the food, assisted by peristaltic movements of the muscles of the 
neck. The development of the vertebrae in this species into knifelike points extending into the rsophagus to cut the egg shell as it passes, is quite unique among snakes. The regurgitation of the shell afterward, as far as the writer can note, is an absolutely unique trait among serpents. Though many of them feed largely upon eggs, the shells of which are crushed in the throat by the reptile forcing that portion of the body against the ground, the fragments of the egg-shell are swallowed and entirely dissolved by the gastric juices.

In considering the relationship of dentition to the feeding traits of non-venomous serpents it is of interest to note that among the typical constrictors there is but little generic individuality in the structure of the teeth. With snakes that feed largely upon warmblooded prey, there is a uniform, liberal provision of strong, recurved teeth. Among those that feed principally upon mammals and birds there is a tendency for the anterior teeth to be the longer and stouter. With snakes that seize a struggling creature to kill it by pressure of the coiling body, this development will be seen to be highly efficacious, although quite unsuited to the non-constrictor, which must entirely manipulate the struggling prey by the work of the jaws alone. The dentition of the constrictor is designed to firmly seize the quarry without further movement of the jaws and draw it within the coils to be killed by strangulation. Some generic individuality in dentition, though along the same lines of enlargement of the anterior teeth, exists among constrictors subsisting largely upon birds. The South American and Madagascan Tree Boas, Corallus, are good examples. The teeth become gradually enlarged anteriorly in both the upper and lower jaws until the extreme anterior pairs might be designated as really fang-like. A structure like this is highly effective in seizing feathered creatures. The long, extremely sharp teeth pierce the abundant covering of the prey and take positive hold. By far the greater number of serpents evincing a tendency to enlargement of the posterior teeth subsist upon cold-blooded animals and are non-constrictors. The writer has recently noted an apparent trait among non-fanged Colubrine snakes that warrants much investigation. This is a certain paralyzing effect of the salivary secretions. The most definite observation related to specimens of South America Tree Snakes-Aehtulla.

The subject of dentition brings us to a similar review of the feeding habits of the venomous snakes. Here we note that among 
snakes with fangs the habit of constriction disappears. It is noted to a slight extent with the Opisthoglypha. Among the Proteroglypha there is but an occasional hint of it, while with the highly specialized Solenogiypha* it is altogether absent.

We will consider the poisonous serpents in the following order:

Two series of the Colubridae, thus:

Opisthoglypha: Grooved fangs situated posteriorly.

Proteroglypha: Short, rigid, venom-conducting fangs developed with internal canal and orifice at tip;

Two subfamilies forming the Viperidae: the fangs situated anteriorly.

The Viperinae and the Crotalinae, with greatly enlarged anterior fangs, that are attached to movable bones.

The Opisthoglyph snakes form a series to which comparatively little study has been devoted. While simpler descriptions have tended to place them among the innocuous species, they are provided with a well-developed fang mechanism and a poison highly efficacious in subduing the prey. A considerable number of the species are of insignificant size, consequently possessing almost microscopic fangs. Some species are large enough to be dangerous to man. The anatomy of the poison apparatus is reversed from that of all other types of venomous snakes, the fangs being furrowed or grooved, and situated in the extreme rear of the upper jaw; while the poison glands are contained within the labial, instead of the temporal region. These snakes may have one, or several pairs of fangs. To imbed these venom-conducting teeth, an Opisthoglyph snake must advance the jaws in a series of the familiar "chewing" motions characteristic of serpents. When the fangs are brought into play, the jaws grip hard. This persistent hold enables the poison to flow down the furrow of the tooth and into the wound.

The writer has made careful note of the feeding habits of snakes of this type that have come to the Reptile House. A considerable number of the Opisthoglyphs are of aboreal habits and it is representatives of this kind the writer has induced to feed. Most of our aboreal species preferred lizards. The attack is a deliberate stalk, the neck is doubled into a lateral loop and the serpent strikes with great rapidity, apparently aiming to secure the victim by the head. The jaws are advanced until the fangs are well imbedded and the prey is killed in significantly quick fashion. The venom appears to act upon

*Members of the Viperidae-the rattlesnakes, copperhead and moccasin; the Old World vipers. 


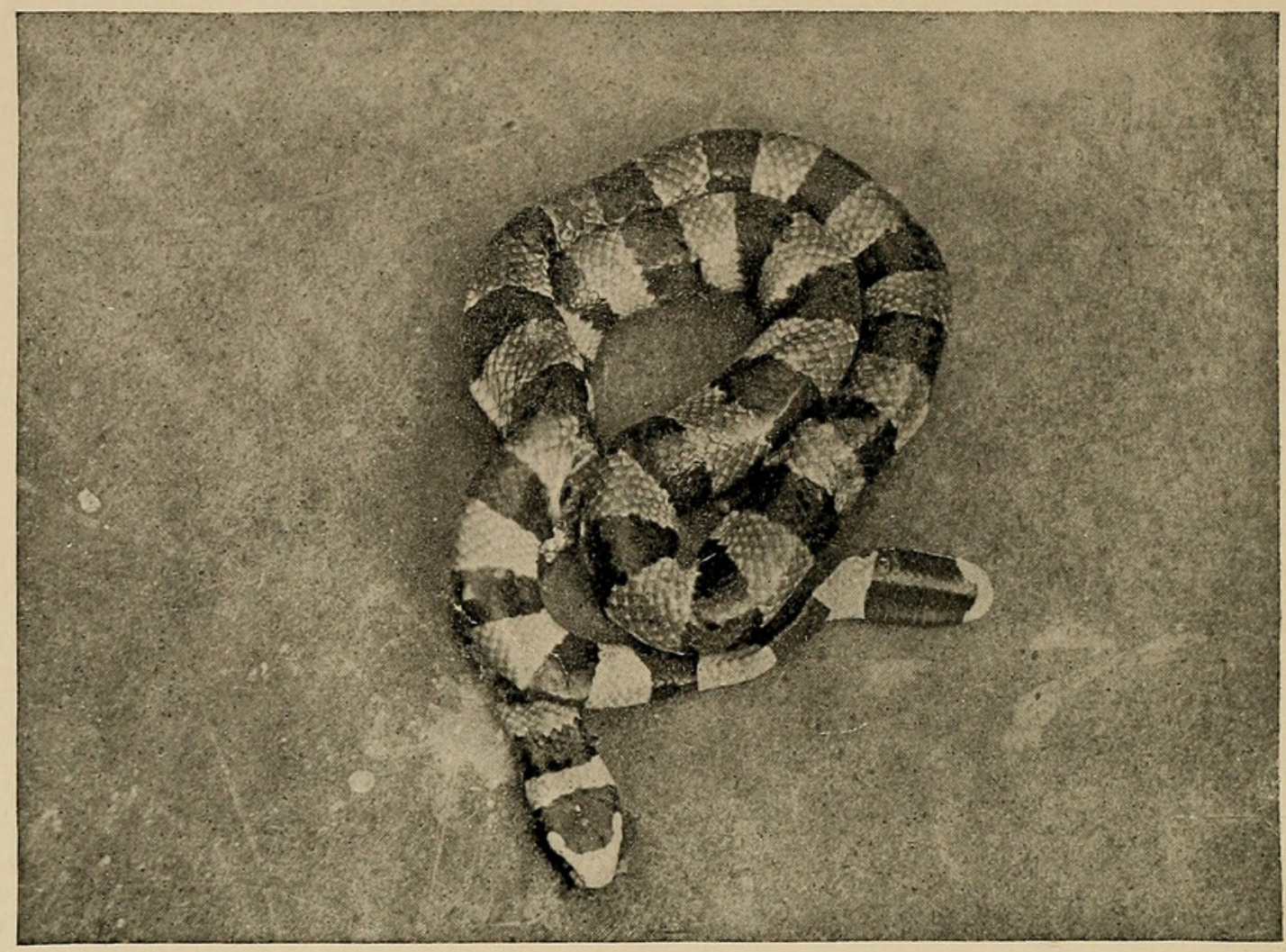

FIG. 81. SEA SNAKE, Platurus schistorhynchus

Venom from a pair of short fangs subdues the prey. The food consists of fish. Snakes of this type abound in the Indian Ocean

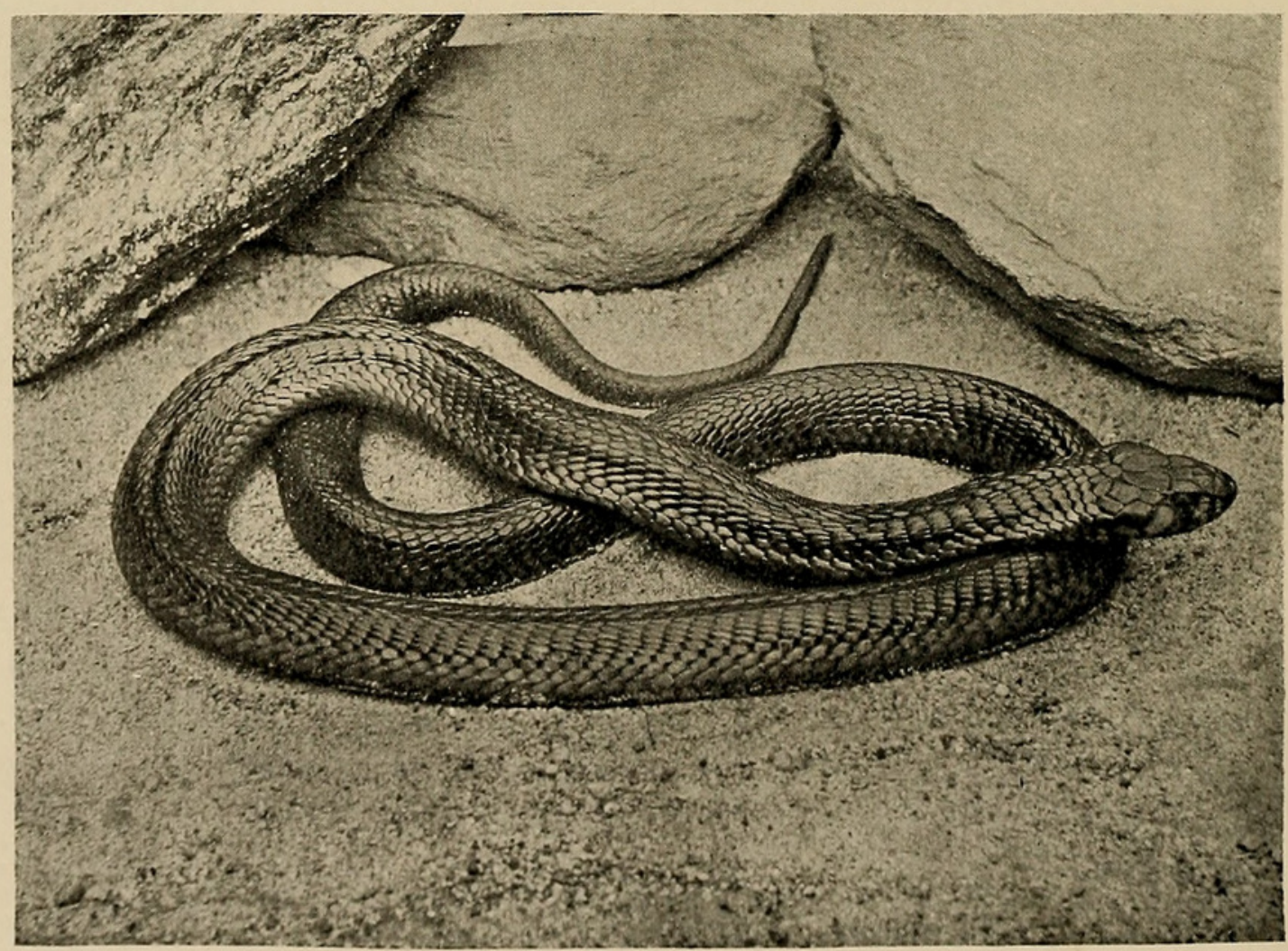

FIG. 82. EGYPTIAN COBRA, Naja haje

Short, venom-conducting fangs subdue the prey, which is gripped by the snake's jaws until dead 
the nerves, benumbing the victim. An Opisthoglyph snake will kill a lizard in less time than a Proteroglyph or Viperine serpent of the same bulk. From one to two minutes may be consumed in rendering a lizard of the size of the common Anolis entirely inert. The writer's observations relate to the South American Tree Snake, Oxybelis acuminatus, the Indo-Malayan Green Tree Snake, Dryophis mycterizans, the American species of Himantodes and the Eurorean Tarbophis vivax. All of the Opisthoglyph snakes retain their hold of the prey until it is dead, then begin to swallow it without releasing the hold.

With the Proteroglypha, ${ }^{*}$ a series of the Colubridae containing two subfamilies, we observe feeding habits quite similar to those of the representatives of the Opisthoglypha, in the retention of hold uron the bitten prey. The present reptiles, however, possess a far more perfect and highly specialized venom apparatus. During the process of evolution into these fanged types, the poison-conducting teeth, primarily grooved, have so folded about the grooves that a transverse section of them shows a well-enclosed internal canal. The poison glands are located in the temporal region, where the masseter muscles in closing the jaws compress these reservoirs, forcirg the venom forward and out of the fangs. The secretion is strongly neurotoxic. The members of the Hydrophiinae, are altogether aquatic; in fact marine. They feed principally upon f.sh, and their powerful venom quickly renders the prey inert. They frequently attack species with long and sharp spines, but the poison so relaxes the muscles of the fins that the snake has no difficulty in swallowing the prey. It is worked about in the jaws until the snout points down the reptile's throat, when actual deglutition begins and the spinebearing fins are pressed against the body of the creature to be swalowed.

The remaining subfamily of the Proteroglypha is the Elapinae, the cobras, kraits, coral snakes and their allies. The greater number of these are strictly terrestrial and the majority are alert and active in hunting their food. From extensive studies of these snakes, the writer has observed a series of feeding manceuvres uniformly similar to those of the non-constrictors of the innocuous Colubridae. The

*A series of the Colubrine serpents. The members have short, permanently erect venom-conducting teeth situated in the anterior part of the upper jaw. The cobras are familiar Old World species. The coral snakes are New World representatives. 
Opisthoglyph snakes with their crude, grooved fangs, and the many highly specialized long-fanged vipers, which we will presently consider, have a marked habit as if strongly appreciative of the deadliness of their fangs, in seizing the prey, firmly imbedding the venom conducting teeth and awaiting without further move, the death of the quarry. Many members of the Elapinae, to the contrary seize the prey, imbed the fangs in a series of chewing motions and commence to swallow it at once. In a large number of cases the prey struggles violently and the snake endeavors to subdue it by various movements of the body, even by partial constriction. The short fangs of these serpents are liable to discharge their venom into the pelage or feathers of a bitten animal, which, during the entire process of deglutition may be quite unaffected by the snake's poison. If the prey consists of another snake, a lizard or batrachian, creatures with comparatively unprotected bodies, the fangs are easily imbedded. The effect of the venom upon cold-blooded prey, however, appears not so rapid as that of the Opisthoglyphs. A great number of the elapine snakes feed upon mammals and birds. In a general summary of their feeding habits, the writer would designate the more highly specialized venom apparatus as compared to that of the Opisthoglyphs, as but slightly more efficient in subduing the prey than that of the members of the latter series. It is possible that the elapine snakes form a group in a state of rapid transition toward the development of larger fangs.

The Viperidae embraces the most highly specialized serpents, owing to the extreme development of the poison apparatus. With these serpents the elongate and horizontal maxillary bones existing among other snakes, have been reduced to small, vertical, movable anterior processes each bearing an enormously elongated fang, with a perfectly enclosed canal and venom ejecting orifice at the needlelike tip. Here the length of the fang is so great that the movable maxillary bones enable these great teeth to be folded back when the jaws are closed. In consequence it is not surprising to find among such reptiles an unique feeding habit adapted to the fang development. This consists of a wonderfully dexterous stabbing of the prey by these terrible weapons, and its immediate release. The bitten animal is able to stagger but a short distance, when it is overcome; it may drop in immediate convulsions. Small animals are often vitally stabbed and instant death occurs from the fang thrust alone. Such are the habits of the larger mammal-eating vipers in attacking 


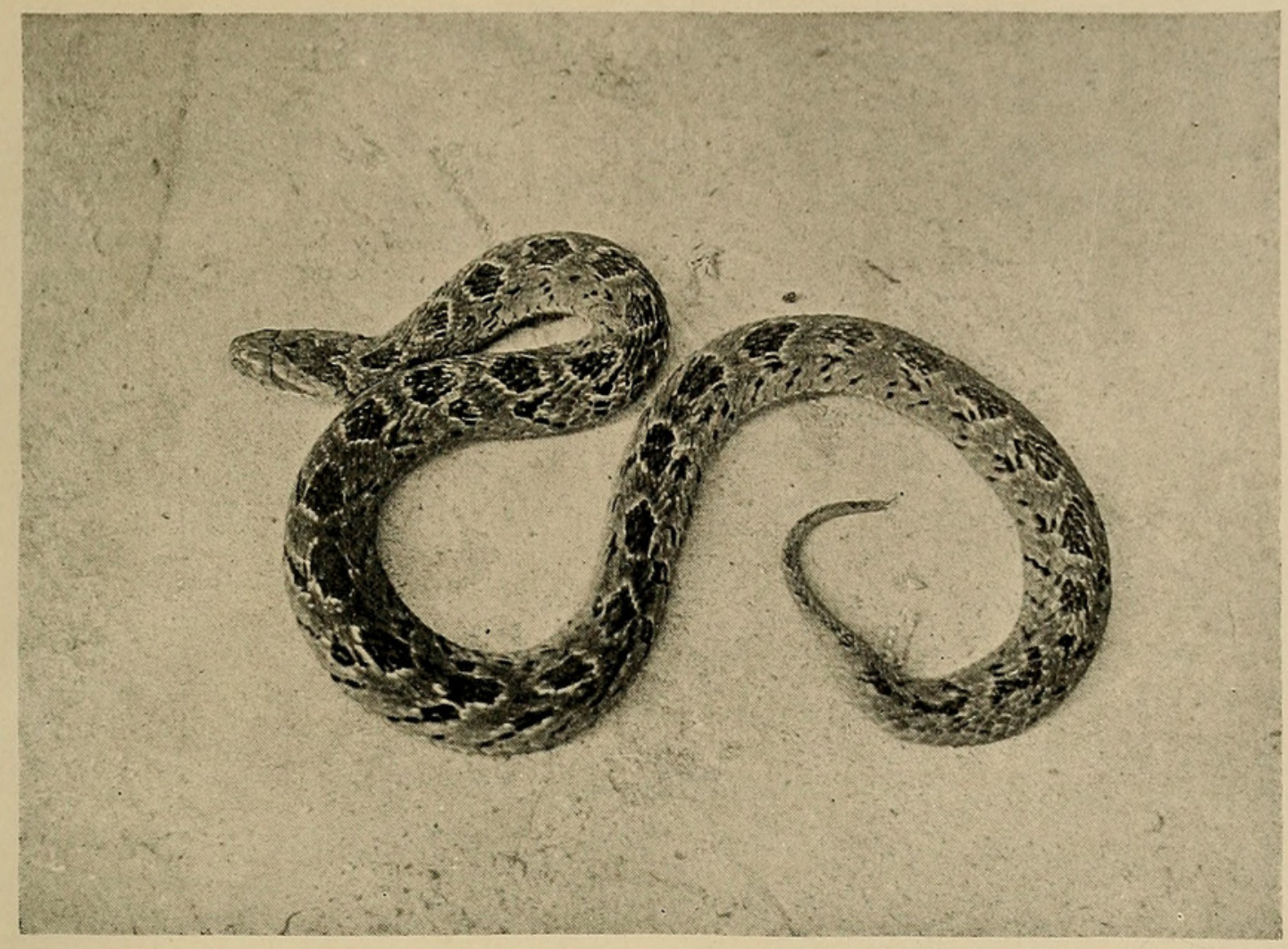

FIG. 83. CAPE VIPER, Causaus rhombeatus. AFRICA

Possessing short, poison-conducting fangs, this snake usually grips the prey in its jaws until the venon takes affect

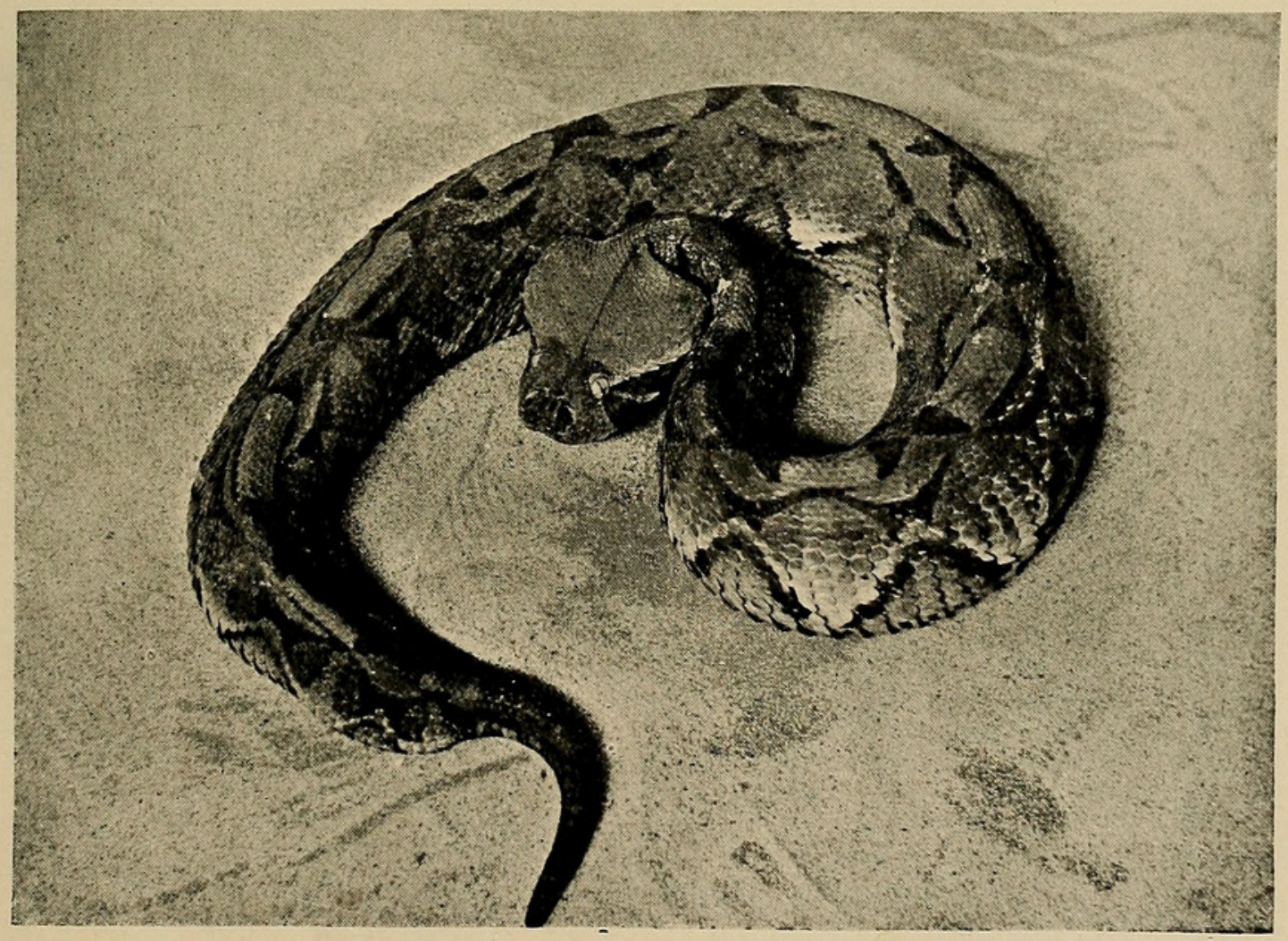

FIG. 84. GABOON VIPER, Bitis gabonica. AFRICA

Owing to the enormously elongated fangs, snakes of this development stab the prey by a biting blow from these teeth, and instantly release the jaws 
prey, which, if held by the jaws might inflict damage in the death struggles by teeth or claws. Some of the vipers, particularly those which feed upon birds, lizards and batrachians, retain their hold after striking, driving the long fangs deeply into the victim.

The writer has endeavored to definitely note by observations of captive specimens and snakes in a wild state, whether or not, as has been alleged, the habit of striking the prey and releasing it is but a nervous and abnormal habit displayed by vipers under observations. At the time of writing he is assured that this is true to a slight extent, but that the habit of simply striking the prey is common with wild snakes. Two observations in the south relate to definite notes of the feeding of the large Diamond-Back Rattlesnake, Crotalus adamanteus. One, a rabbit struck while in the undergrowth, struggled out on a sandy road to die and was followed by the snake, which consumed the rodent; the other, a tame rabbit, bitten while prowling under the foundation of a hut, dashed into a clearing and was later followed by the snake. The writer has noted one observation of a wild Timber Rattlesnake, Crotalus horridus and a young chipmunk. In the latter instance the chipmunk ran fully twelve feet before overpowered by the poison and died under a flat stone. Immediately after biting the animal, the snake started leisurely in the direction whence it ran and located the quarry without difficulty. In contrast to the habit, the writer has observed a wild rattlesnake of rather small size bite and hold a short-tailed mouse.

The writer believes that the viperine snake displays a considerable amount of caution in the treatment of its prey. These excessively nervous snakes are also liable to mislead the observer in tracing normal habits, when the reptiles are studied in captivity. There is little doubt that the jaws retain their hold upon more helpless prey if the snake is feeding in its natural environment. Alert, and always anticipating danger as a captive, the reptile under such conditions strikes and immediately frees the fangs in order to be on the defensive. These theories appear plausible when we note the contrasting habits of the very nervous rattlesnakes (Crotalus), and the more phlegmatic moccasin and copperhead snakes (Ancistrodon). The former, as captives usually strike all animals offered as food; the latter seize all prey and hold it unless it be of the larger rodent type that is liable to injure the snake. Among a number of rattlesnakes of different species reared in captivity and consequently far less nervous than those caught wild, the tendency was to strike and 
release rodents, but retain the hold upon birds. Despite this variance in subjugation of the prey, we have noted with the members of this family, a feeding trait possible only with the development of the present highly perfected fang mechanism.

\section{Part II.-The Food of Serpents}

In considering in detail the food of serpents, the writer has placed his observations in the order of classification relating to these reptiles.

The Typhlopidae and Glauconiidae: These small, lowly and ancient types of serpents are persistently subterraneous and appear to be largely insectivorous. The chitinous coverings of insects are to be found in dissected specimens, and examples are commonly dug from termites' nests, gorged with these insects.

The Boidae: The Boas and Pythons, of direct ancient lineage as evidenced by their possession of vestigial hind limbs, feed largely upon mammals and birds, although the big tropical lizards are also preyed upon by some of the species. The Anaconda, Eunectes murinus, is by far the largest of the New World serpents, and detailed investigations show the food to consist of wild swine (the peccary), monkeys, the larger rodents and various species of water fowl. Although an aquatic serpent, the anaconda, even in an immature state, does not appear to feed upon fish or amphibians. The various species of South American Boa feed upon the larger rodents and birds. While students of the habits of these big constrictors have alleged that the food is restricted to warm-blooded prey, the investigations of Mr. R. R. Mole, Port-of-Spain, Trinidad, have demonstrated a marked appetite among these snakes for iguanas, tegus and other big lizards. The Society is indebted to Mr. Mole for a large number of the tropical American snakes to be exhibited in the Reptile House and for valuable notes on the habits of various South American reptiles. Herewith annotated are several observations by Mr. Mole:

"I do not know whether you are aware of it, but the great snakes are very fond of lizards. They are more easily digested than mammals and birds. Boa constrictors can rarely resist the temptation of a big tegu, and my Indian pythons (molurus) have swallowed many iguanas and one devoured a vigorous four-foot alligator." 
In their combats with the more sturdy prey, the big constricting snakes are often badly wounded. Old specimens show numerous scars which often point to once existing wounds that barely escaped vital parts. As evidence of these conditions the writer again quotes a communication from Mr. Mole:

"As you are interested in big anacondas, you may like to know that I have an immense beast now. Although she is not enormous in girth, she is very bony and gaunt, and actually measures (I have taped her), seventeen feet! Her skin hangs loosely upon her, and yet in this condition she weighs 104 pounds. Thin as she is, this snake is impressive. As it is not long from the time when these snakes give birth to young, this may account for her emaciated condition.

"She was captured by the men who captured Big Annie*, and when I first saw this new specimen, I thought they had caught her with a forked stick with a spike in the fork. They solemnly swore that this was not so. Nevertheless, she had a punctured wound about one inch behind the line of the eyes, and almost in the center of the back of the head. I got her into a large tank, and from later indications I was led to believe that she had fed upon an ant-eater. I found an immense claw which I supposed belonged to Tamandua tetradactyla. Further examination revealed pieces of hair which made me positive that she had swallowed a large specimen of our ant-eater.

"A few days after this I saw the men who captured her, showed them the claw, and they agreed with me, asserting what I had never thought of - that the Matapel (dog killer), our local name for this anteater, had made the wound in the anaconda's head, which I now think quite likely. I annointed this wound with a healing balsam, and the snake now seems tolerably well, although there is a likelihood of the wound breaking out again. I am going to try to feed this snake with rabbits, in the manner prescribed in your book on reptiles. She has one or two superficial wounds about the body, and I am sure the Matapel did not succumb before he had made a terrific fight for life. They are dreadfully strong beasts, and their claws are powerful, long and sharp.

"The other day a dead boa constrictor was brought to me. I think it was larger than Castro. I taped it and it measured eleven feet and seven inches in length, and was thickly built. It seized a

*A nineteen-foot Anaconda on exhibition in the Park. 
hunting dog and the dog's owner was so afraid that it would kill the beast, ('it had lapped it up', he said), that he destroyed the snake. It was a wonderful specimen, and I told him that it was worth forty of his wretched curs, such as are used by the peasantry in what they call hunting."

As captives the various species of New World Boidae are fairly hardy; the species of Boa, Epicrates and Corallus feeding readily upon rodents and birds, although members of the last-named, arboreal genus prefer birds to other prey. The anaconda does not feed so readily, and when it does, our specimens prefer fowl. There is often great difficulty in inducing freshly-caught, adult examples to feed. While the majority of the New World Boidae will feed at any time of the day, we have found those anacondas under observation that were inclined to feed, to be particularly disposed to take their prey at night and a few specimens have been induced to feed only at such times. These habits do not pertain to very young examples of the species, two large litters of which we have studied in rearing. The very young snakes, voracious at all times, appear to prefer birds.

The writer's observations of the Old World Boidae are fairly complete, having embraced the following species:

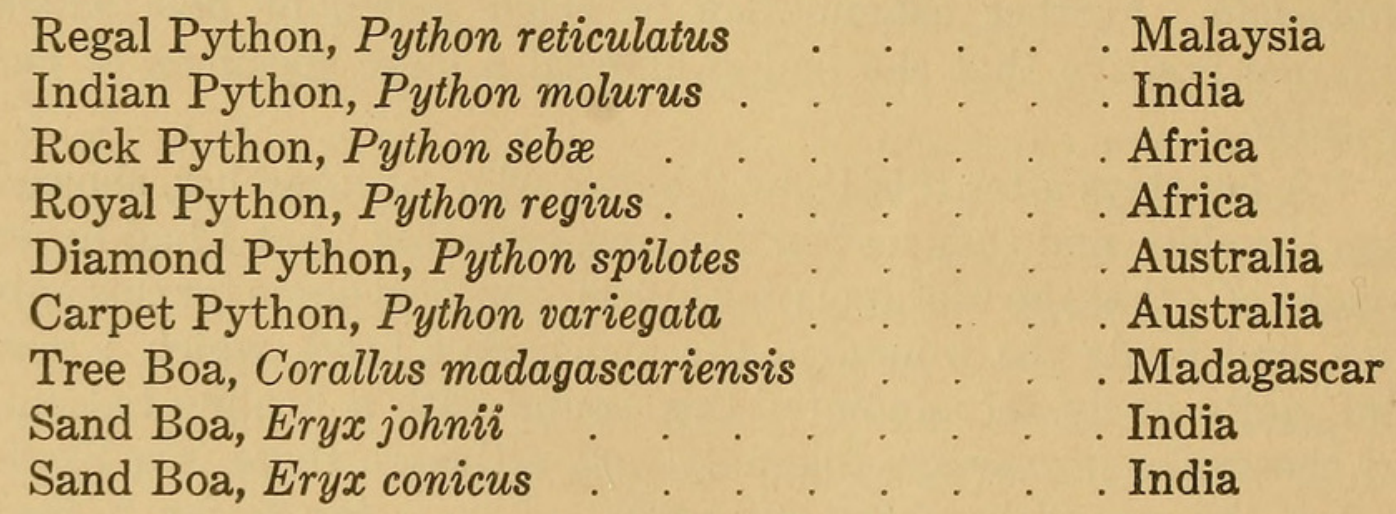

The food of Python reticulatus is particularly interesting, as this species attains the greatest length and bulk of any known serpent. About a dozen of these superb reptiles have been under the writer's observation, and while the food of the species may be said to consist of various mammals and birds, there is a marked individuality among captive specimens in the preference of different types of food.

From repeated examinations of the crates of newly arrived specimens of $P$. reticulatus, both at the Park and among the several large animal dealers, the writer is convinced that the big specimens 
when in their native environment, feed often upon the Indo-Malayan wild swine. Examination of the excreta in sixty per cent. of a series of about forty specimens investigated showed liberal traces of the bristles of Sus cristatus, and in numerous cases the horny coverings of the feet. From several crates enclosing snakes of a length slightly over twenty feet, were taken hoof coverings that were estimated to have been those of wild hogs of at least seventy-five pounds weight. Many captive specimens of this great snake refuse all other food but swine, and examples twenty feet in length, swallow a fifty-pound pig without difficulty. An occasional specimen will refuse all other food but fowl. A sixteen-foot snake of this species, would take at a meal, two eight-pound roosters. These big snakes do best if fed at intervals of ten to twelve days. At intervals like this they feed regularly for five or six months when there is an inclination to fast, this condition being stubbornly continued for three or four months. This fast is evidently an instinctive trait that relates to seasonal conditions in the natural environment. Most tropical snakes evince like habits and the writer has observed that those which are voracious enought to feed steadily throughout the year accumulate excess fats, which so derange the important organs as to cause such reptiles' deaths. It is only during the past three years that we have been making regular schedules of the feeding of our more valuable reptiles, and subjecting them, if they do not seem so inclined, to an annual fast of several months duration. This process has quitereversed our former records of the longevity of a number of captives representing tropical species. The writer is convinced that the impossibility of keeping alive the big tropical vipers for more than a year's time has resulted from feeding during a period when the animal has secreted fatty sustenance to carry it past a period of hibernation or æstivation, as the case may be. In support of this view he cites the results of various post-mortems of apparently over-nourished reptiles, in which an undue fatty condition has brought about marked changes in the liver and attendant organs. This annual fasting period particularly appeals to the boas and pythons, which are of peculiarly delicate organization that responds quickly to changes of temperature and undoubtedly affects the feeding habits of these reptiles during the well-defined seasons in the tropics. It should here be understood that the tendency among all reptiles to secrete fatty nourishment to be utilized in periods of prolonged fast, is by far the most pronounced among the snakes. Among notes at hand, the writer is able to quote 
the unbroken fast of a specimen of Python reticulatus, that continued through a period of eleven months, and another that covered thirteen months' time. Both of these snakes commenced feeding voluntarily and were strong enough to perfectly assimilate their food. In the prolonged fasting of exceptionally valuable examples, the writer has often resorted to force-feeding. In the compulsory feeding of a python about twenty feet in length the writer kills four mediumsized rabbits, removes the skin, then ties the animals together, the hind legs of one to the neck of another; brown twine being used in this treatment. The snake is taken from the cage and held as straight as possible by eight or ten men, when the rabbits are forced down the reptile's throat for a distance of fully six feet. Several of our big pythons have been fed in this manner for periods of about a year. All were brought to a state of perfect nourishment and commenced feeding voluntarily.

The feeding habits of $P$. molurus are quite similar to its larger Malayan ally; some specimens taking nothing but fowl, others, rodents and small swine. Having noted Mr. Mole's reference to the fondness of pythons for alligators, the writer believes, that as the species of the big snakes are more or less semi-aquatic, they often feed upon the various crocodilians that teem in the regions inhabited by these large constrictors. The African pythons are not so hardy as captives as the Indo-Malayan species.

Corallus is a genus of arboreal boas of eccentric distribution, occurring in tropical America and Madagascar. The species prefer birds and are well adapted in seizing the prey by the possession of greatly developed, fang-like anterior teeth in both upper and lower jaws. The small sand boas of India, $(E r y x)$, feed upon lizards and small rodents. Among the several small families of apparent relationship to the Boidae, the habit of constriction seems common in overpowering small mammals and lacertilians.

The Colubridae: The members of this elaborate family feed upon mammals, birds, other reptiles, amphibians, fishes, crustaceans and insects. It is with certain groups of species of this family that we shall consider serpents of economic value to the agriculturist. Passing the first series of the Colubridae, the Aglypha, all the members possessing solid, recurved teeth, and the subfamily Acrochordinae, composed of river snakes living upon fish and small crustaceans, we will consider in detail the subfamily, Colubrinae, containing the 


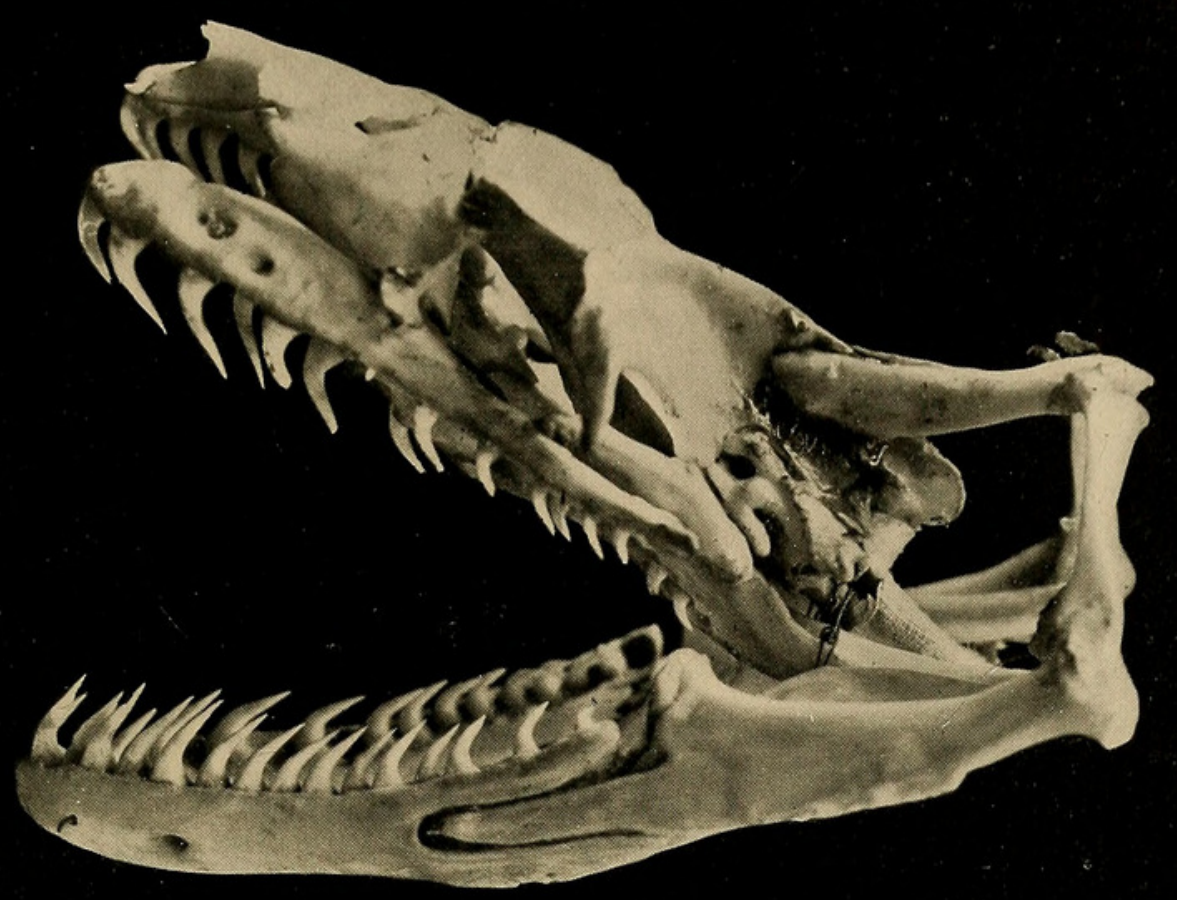

FIG. 85. SKULL OF BOA, Boa constrictor

There is a tendency for moderate enlargement of the anterior teeth-to be noted with all mammal and bird-eating snakes

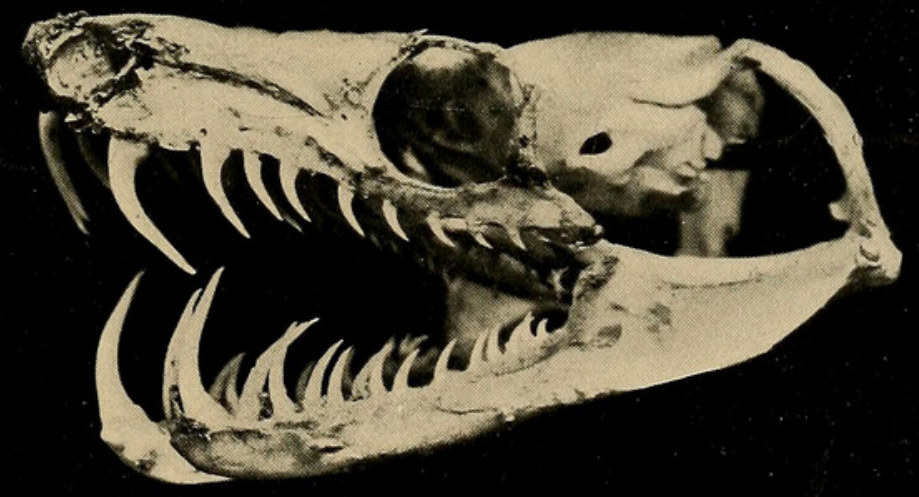

FIG. 86. SKULL OF TREE BOA, Corallus cooki

The greatly enlarged, anterior teeth appear to assist the reptile in positively grasping feathered prey 
typical, non-venomous snakes. The relationship of our first group of genera represented by species under observation, may be simply expressed as follows:

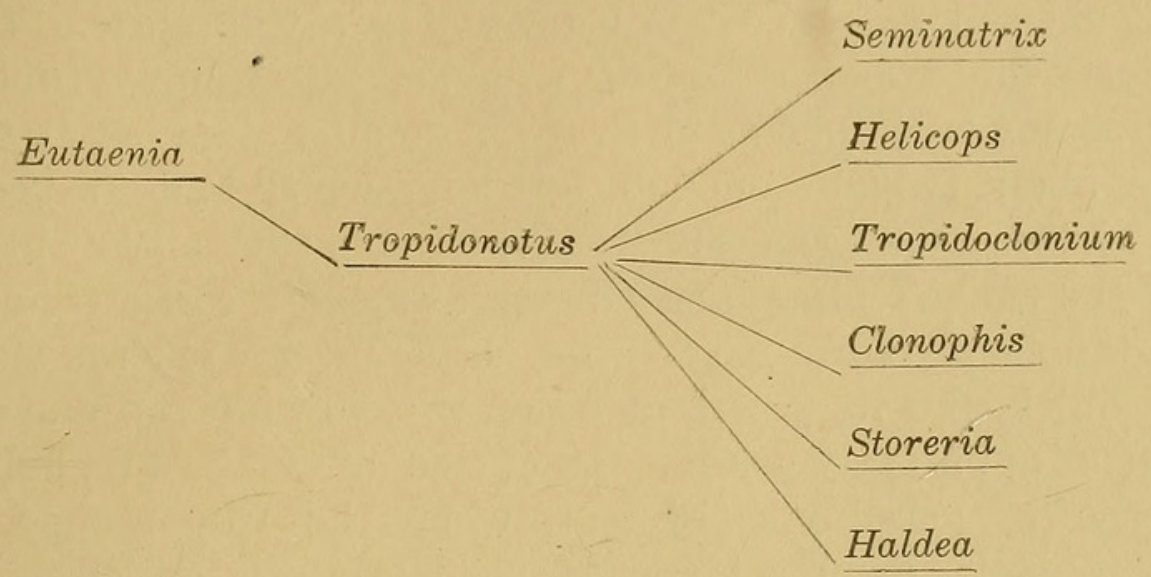

- All of the species are viviparous, and subsist altogether upon cold-blooded prey. With the exception of Storeria and Haldea, the members of these genera are semi-aquatic, although some of the species of Eutaenia seldom enter water. However, Eutaenia and Tropidonotus are closely related, the former possibly an immediate off-shoot of the latter. Hence comparison is of interest.

While the species of Tropidonotus quite persistently confine their feeding to amphibians (batrachians), fishes, crustaceans, in fact the creatures of the river banks and marshy places, we note a variance in the diet of those species of Eutaenia that have become quite terrestrial and hence removed from a feeding ground generously supplied with amphibians and fishes. These have the habit of preying upon earthworms. The writer has failed to induce any of the North American species of Tropidonotus to take such food, nor will the semi-aquatic species of Eutaenia, like $E$. saurita, sackeni, proxima or radix eat earthworms. The upland forms of Eutaenia, however, such as $E$. butleri, $E$. sirtalis and $E$. elegans will feed voraciously upon them. There is no individuality among specimens to be noted here. The variance of habits in Eutaenia, as stated, relates strictly to the respective species involved, and is evidently a necessarily acquired trait in a change from the ancestral lurking places.

Feeding generally upon frogs, toads, salamanders and fishes, the species of Eutaenia cannot be rated as of economic value. Their depredations among frogs and toads, particularly the latter would, 
if anything, place them among those species detrimental to the interests of agriculturalists, although the worm-eating habits of the common $E$. sirtalis should be rated as an economic trait. It is of interest to observe the feeding habits of a representative of the above genus, a specimen of $E$. saurita, noted while in a wild state. The writer witnessed an example feeding in a belt of swampy timber. The high rasping croak of a small frog, directed his attention to the ribbon snake, about two and one-half feet long, which had grasped the frog by a hind leg. So vigorous were the frog's efforts, that it tore itself from the snake's grasp and started away in a series of rapid hops, with the reptile in pursuit. The serpent's movements were amazingly quick, and its power of vision in following the movements of the frog apparently acute. It darted after the amphibian for a distance of possibly eight feet, when the frog stopped, having secreted itself among some leaves. The snake also paused, but was all attention, with neck upraised and constantly darting tongue. It prowled about in frenzied fashion, when a movement of the frog attracted its attention, and it was instantly upon it, this time retaining its hold until the prey was swallowed.

The species of Tropidonotus feed upon frogs, toads, salamanders and newts, the larval forms of these batrachians, fish and crustaceans.

The fresh-water snakes are of no economic value to man, and in the vicinity of streams or ponds stocked with game fish, are a menace to the breeding of the same. These snakes are very prolific, the larger species producing litters of from forty to seventy young. The young feed principally upon fish, remaining close to the water, while the older reptiles often prowl the marginal vegetation for frogs and toads. The manner of capturing fish shows a strong adaptation to aquatic life. Prowling along the bottom, the snake watches for prey above it. With the prey in sight, the snake rises and with a snapping, whiplike motion of the neck and head, the jaws widely distended, reaches for the food. It is in this manner that the young snakes enter schools of small fishes. The young reptiles seldom pursue individual specimens. With the food swallowed, the school is again stalked and the manoeuvres continue until the reptile is gorged. These snakes are able to swallow their prey while under the water. A three and a half foot specimen of $T$. fasciatus sipedon, immediately after capture, disgorged eleven "suckers" or mud fish, averaging three to four inches in length, three sunfish, with strong, 


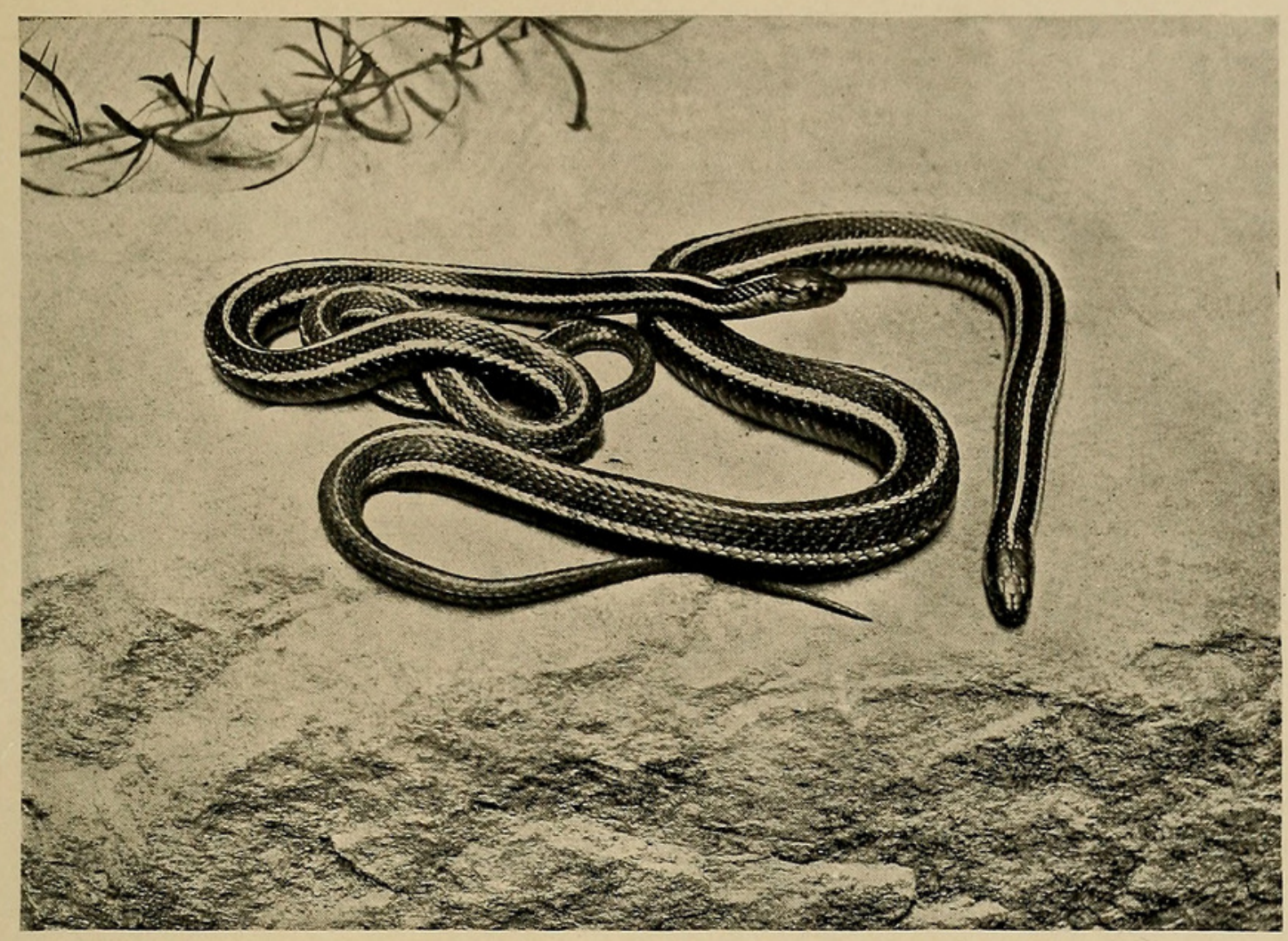

FIG. 87. STRIPED SNAKE, Eutaenia butleri

Serpents of this kind are of little or no economic value. The food consists largely of batrachians. Inhabits the Central States

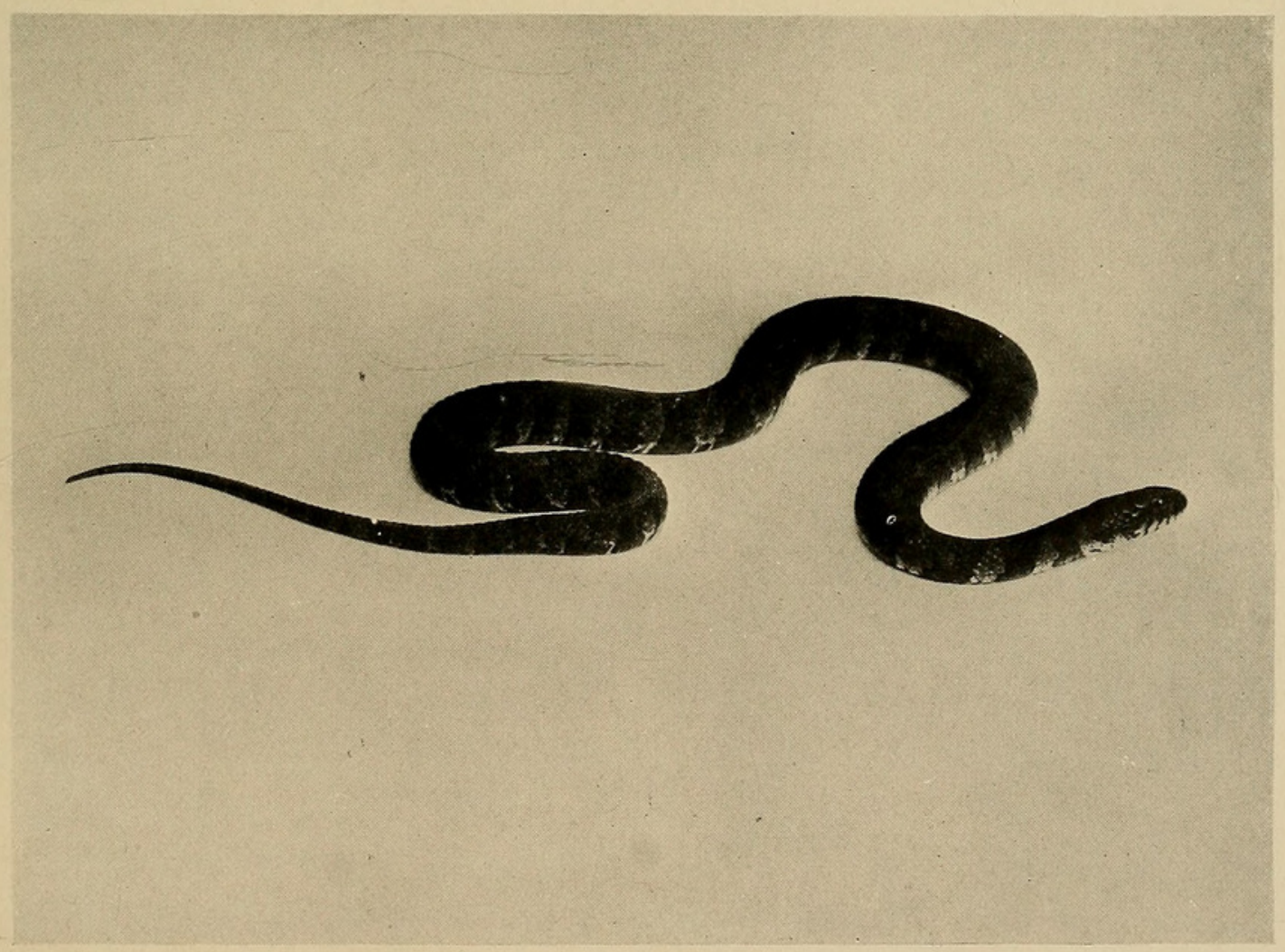

FIG. 88. COMMON WATER SNAKE, Tropidonotus fasciatus sipedon

This abundant reptile of the eastern United States is a menace to streams stocked with game fish 
dorsal spines, and a crawfish, or fresh-water crustacean of fully four inches in length, with formidable mandibles. Some of the persistently aquatic North American species of Tropidonotus, as T. cyclopium and T. taxispilotus indicate a certain degree of specialization in having the eyes placed further forward and nearer the top of the head denoting better adaptation to life in the water. These species are particularly partial to fish, and a great number of captive examples refuse all other food.

Seminatrix, Helicops, Tropidoclonium, Clonophis, Storeria and Haldea are apparently off-shoot genera of Tropidonotus. The mode of life has varied and while some are persistently aquatic, others are quite terrestrial. We note among the members of all the genera, the tendency of the development of enlarged posterior teeth to assist these non-constricting types in retaining their hold upon their coldblooded prey with its comparatively naked integument that is easily pierced by such dentition. The single, North American, species of Seminatrix, is apparently a degenerate type of water snake. The strongly keeled scales of Tropidonotus are indicated by hair-like lines on a smooth scalation. This snake leads a secretive life near the borders of streams and feeds upon small batrachians. As a captive it refuses fish. Tropidoclonium and Clonophis are of similar habits. Storeria and Haldea appear to be of degenerate relationship to the Tropidonotus and Eutaenia types. The size is small, seldom exceeding twelve inches, and the food consists almost entirely of earthworms. With the South and Central American Helicops we see pronounced specialization toward the aquatic type. The eyes are set at an oblique plane with the top of the head, and these serpents prefer fish to any other food.

Passing from the genera just considered, we come into consideration of several genera which fall into a rather crude group. Attending their appearance in technical check lists is a number of other genera which are herewith eliminated owing to their species not having been studied. Those that we will group here are Zaocys, Zamenis, Salvadora, Phyllorhynchus, Drymobius, Spilotes, Coluber, Herpetodryas and Dendrophis. Among these we find the predominating number of species to be those feeding largely upon warm-blooded prey, some that evince the power of constriction feeding exclusively upon such prey, others to a lesser extent, a few merely indicating this characteristic in their manipulation of the prey or food, and others evincing no trace of the habit. With Zaocys of Southeastern 
Asia, and Zamenis, the latter with twenty-eight species inhabiting the New and the Old world and having among its representatives our familiar black snake, we note the characteristic of semi-constriction. The species are omnivorous as regards the feeding habits of serpents, as they prey upon small mammals, birds, other reptiles (serpents and lizards) and amphibians, although the writer has never been able to induce a serpent of either of these genera to feed upon earthworms.

Zamenis:-Among the species of this genus are several North American snakes that must be rated as of economic value. While they prey to a certain extent upon amphibians, they only occasionally feed upon frogs. They seldom or never attack those amphibians with granular skins, like the toads, and several species of the more terrestrial frogs; hence we might eliminate from their diet, those species of amphibians which are particularly beneficial to the agriculturist. Of slender form, and very active, they hunt for rodents within their burrows, destroying the young and pursuing the adults.

Well-known Old World species of Zamenis are the Indian Rat Snakes, $Z$. korros and $Z$. mucosus. Familiar New World types are the Black Snake, Z. constrictor and the Whip Snake, Z. flagelliforme. Both frequent rather open places, being partial to the edges of meadows where they hunt their prey in the neighboring brush or in stone walls. Here they feed largely upon the smaller rodents, which tend to damage the products of the farmer.

From his studies of the separate species of Zamenis in captivity, the writer has noted that the Black Snake evinces a preference for the smaller rodents. It will also eat birds and the various species of smaller snakes, although it does not attack the poisonous snakes as has often been alleged. The writer has noted it feeding upon individuals of its own species, and the closely related whip snake. It will take lizards and is exceedingly active in catching these. Frogs are also eaten, but among these are several species that the snake will grasp and immediately reject. An example of this type of batrachian is Rana palustris, which exudes an irritating secretion from the skin. Toads are never eaten, and there is a disinclination to feed upon the tailed batrachians, owing possibly to their irritating skin secretions, although many small snakes feed upon them.

$Z$. flagelliforme, the Whip Snake, is of rather different feeding habits. It is particularly fond of small rodents and birds, occasion- 


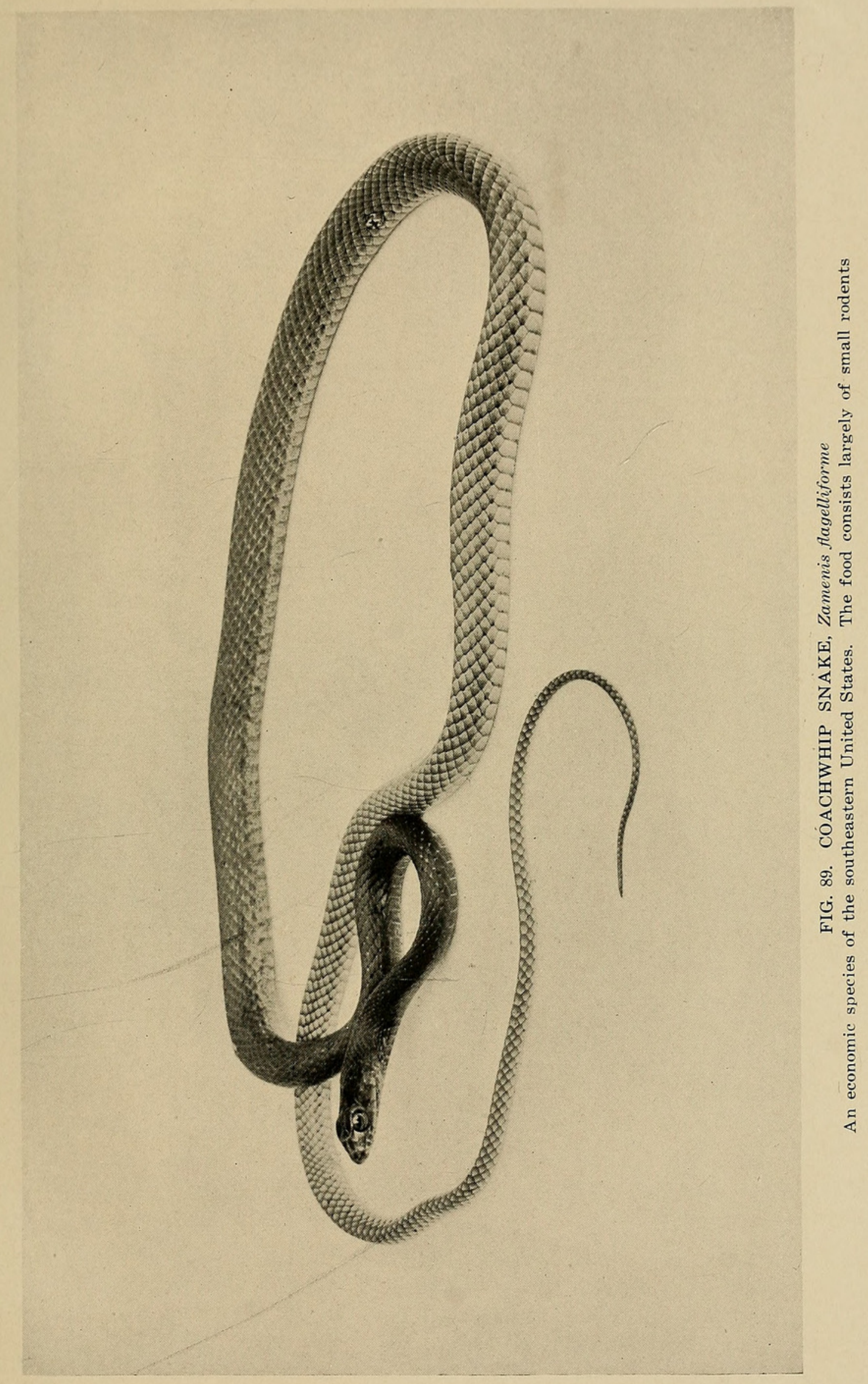


ally feeds upon other snakes and lizards, but seldom can be induced to feed upon frogs. These habits relate generally to the different species of Zaocys and Zamenis, some having a wider range of diet than others, a few feeding almost entirely upon lizards and other small snakes.

Before considering the feeding habits of the other genera mentioned, it is of significance to state that among the species of the subfamily Colubrinae, the tendency is for the viviparous species to subsist upon cold-blooded prey, while the great majority of the oviparous species subsist upon warm-blooded animals, or a mixed diet of warm and cold-blooded creatures. All of the species in the present group of genera are oviparous.

Salvadora and Phyllorhynchus are apparently off-shoot genera from the Zamenis type. Their distribution involves dry and arid regions, and we note the food of Salvadora to consist of lizards and small rodents. The feeding habits of Phyllorhynchus are practically unknown, but judging from structure, it apparently feeds upon small lizards, other snakes and possibly the young of the smaller rodents. Drymobius is a genus of the warmer latitudes and its members feed largely upon batrachians, lizards, and occasionally although not frequently, upon small mammals and young birds. Spilotes stands intermediate in relationship between Zamenis and Coluber, two important genera with a considerable number of aprarently related forms. The species of Spilotes are particularly interesting in their feeding habits, as they are quite omni-carnivorousfeeding upon lizards and snakes, all types of batrachians, including the toads, which lack of preference in the selection of prey among creatures that greatly vary in a possession of highly irritating skin secretions, is quite unusual for serpents that also prey as often as occasion permits, upon mammals and birds. The species of Spilotes must be regarded as of considerable economic value, as mature examples are bold hunters and ever on the alert for rats and mice. Highly active, they feed more frequently than many serpents, and while noting this trait, it is of importance to state that the feeding intervals of various serpents are positively governed by the characteristic activity or inactivity of the reptiles involved. As examples of the inactive type the writer quotes the members of the Boidae, which if fed at intervals of twenty days apart will remain well nourished, while serpents of the type represented by Spilotes, 
Zamenis and the like must be fed at intervals of four to six days, or they soon exhibit emaciation.

The large and important genus Coluber made up of New and Old World species, is composed of snakes of considerable economic value. Several important and useful species inhabit the southeastern portion of the United States, where are to be found the Black Coluber, C. obsoletus, the Four-Lined Coluber, C. o. quadrivittatus, the Gray Coluber, C. o. confinis, and the Corn Snakes, C. guttatus. All of these snakes feed upon rats and mice, although their food also consists of birds. Their depredations among the birds, however, are quite counterbalanced by their useful work in destroying the small mammals that are a menace to grain and other products of the agriculturist. With the great majority of the species of Coluber there is a decided tendency to feed exclusively upon warm-blooded prey. The writer has had under observation a generous proportion of the species of this genus, both the European and American, and in his continuous studies covering a period of over fifteen years, has not induced one of these snakes to feed upon any type of batrachian. Very rarely, these snakes have been noted to feed upon lizards, although they seldom or never exhibit a cannibalistic tendency common among the serpents of the other genera under immediate consideration. Summing up the feeding habits of the genus it is appropriate to describe these powerful constrictors, as snakes of economic importance that feed almost entirely upon mammals and birds. Pituophis, an American genus of large and powerful constrictors, embraces quite similar habits, and one species in particular, the Bull Snake, Pituophis sayi, is a reptile of such great economic value throughout its habitat, that it might be introduced and protected in the great grain belts of the United States, as a common enemy to the several species of highly destructive ground squirrels or spermophiles.

Of apparent relationship to the genera considered in the preceding paragraph, the writer quotes Herpetodryas and Dendrophis, that have assumed marked arboreal habits, with a consequent change of food. With Herpetodryas we note the interesting trait of a fondness for birds, which are readily captured in the low bushes or trees inhabits, and also a liking for frogs and fish. Several members of this genus apparently waver in the development of their mode of living, between an arboreal life and a semi-aquatic existence. They often dive from the trees into the water in seeking amphibious prey, but the writer has not induced any species of this genus to feed upon 


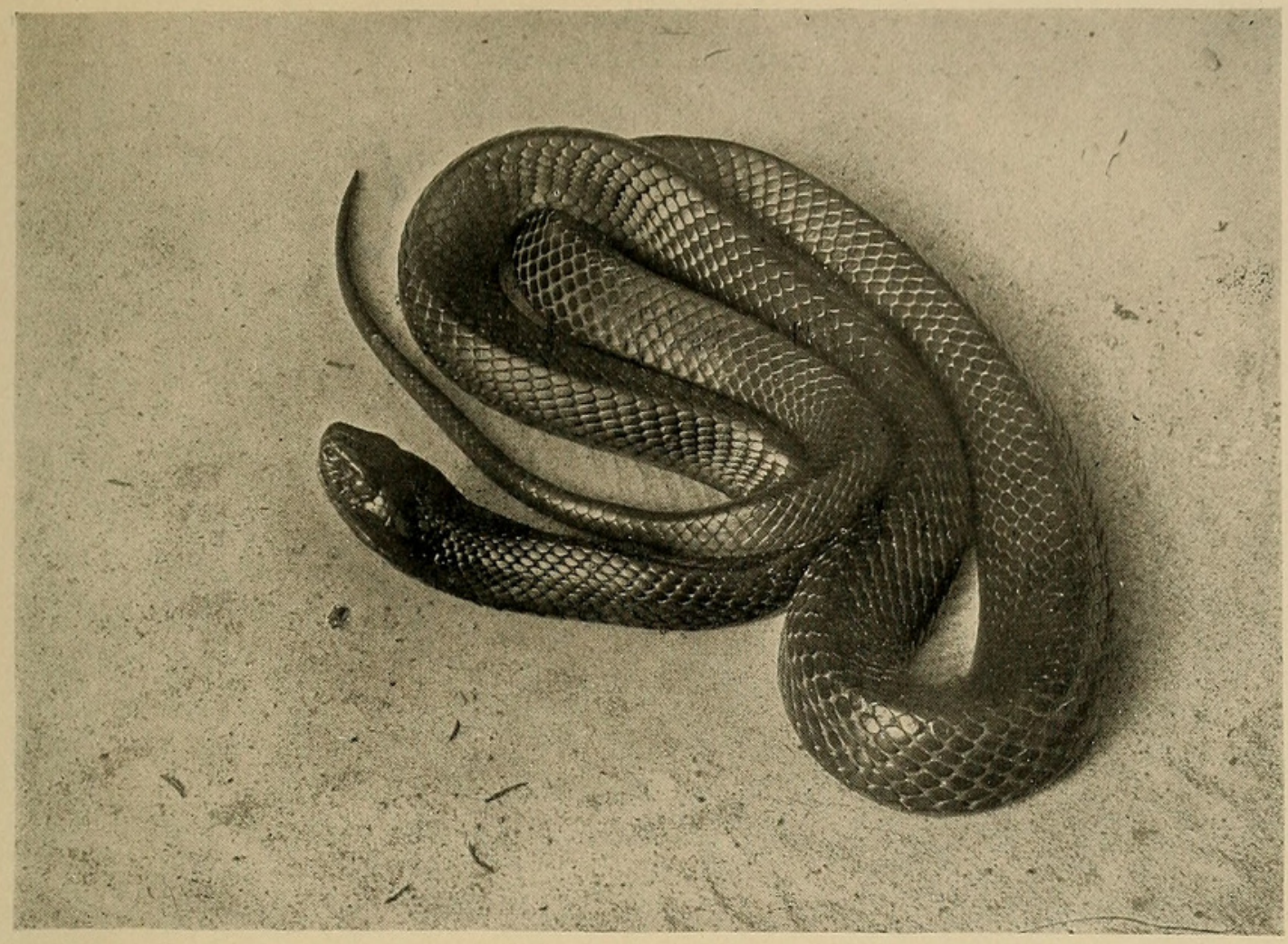

FIG. 90. INDIGO SNAKE, Spilotes corais couperi

Found in the southeastern portion of the United States. Of economic importance

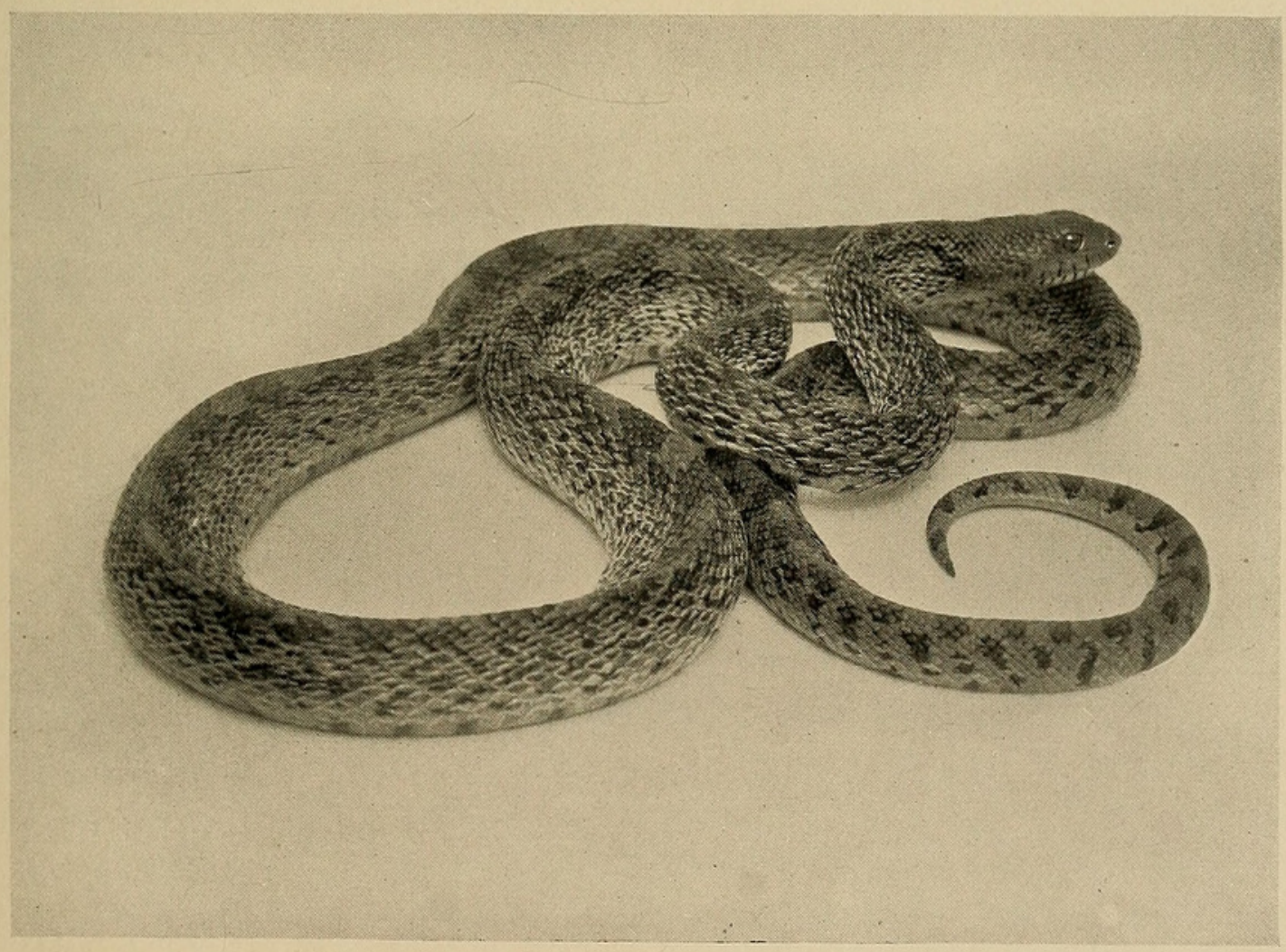

FIG. 91. BULL SNAKE, Pituophis sayi

A species of high economic value in the Plains Region of the United States 
mammalian prey. Dendrophis is a strictly arboreal genus and the food appears to be confined to tree-lizards and such batrachians as can be found among the branches; the food animals of the latter type consist of small species of Hyla.

Passing through the maze of Colubrine genera, it is possible to select another group of related forms, a number of representatives of which have been under observation. These are the genera Coronella, an Old World genus of six species; Ophibolus, the King Snakes of North America, Mexico and Central America (seven species); Diadophis, the Ring-Necked Snakes of the United States and Mexico (three species); Rhinochilus, the Sharp-nosed Snakes of the United States and Mexico (three species); and Cemophora, the Scarlet Snake of the southeastern United States. Close relationship is clearly indicated by well-defined feeding traits. All of the species are proportionately powerful constrictors; and all are oviparous. Without exception, they exhibit cannibalistic habits in feeding upon other serpents and lizards. With the exception of Diadophis, which is apparently a degenerate off-shoot of Ophibolus, the species of the entire group also feed upon small mammals. A peculiarity of these snakes is their utter lack of interest in the batrachians, the frogs, toads and salamanders, although evincing a marked appetite for cold-blooded prey in the shape of other reptiles. In this habit, the rather insignificant species of Diadophis are exceptions as they feed largely upon earthworms and salamanders, although showing relationship to the ancestral group in also feeding upon other small snakes - a rather unusual trait for a very small serpent. One trait of notable specialization away from the parent group as exhibited by Diadophis is shown in the retention of the eggs until the embryos are well developed. Thus, with an oviparous species, the young hatch within about thirty days after the eggs are deposited, opposed to the eight or ten weeks required for the incubation of the eggs of the other species involved. As before noted, we may trace among the oviparous or viviparous Colubrine serpents a rather definite indication of preference for warm or cold-blooded prey. This indication is again evident with the present group. Coronella, Ophibolus, Rhinochilus and Cemophora are composed of species depositing eggs with thread-like embryos and requiring a considerable period for incubation. All of the species feed to a considerable extent upon small mammals. With Diadophis, branching from these forms, and restricting the food to cold-blooded creatures, there is the tendency, as 
with the strictly viviparous reptile, of retaining the eggs in the oviducts, at least until the embryos are well on their way to development and growth, the formation of the scales and appearance of the coloring pigment.

With the species of Coronella, Ophibolus, Rhinochilus and Cemophora, we again note an unusual condition among serpents. Although apparently feeding as generally upon other reptiles as upon small mammals, and occasionally birds, they may not be termed omni-carnivorous as they do not feed upon the amphibians. In this respect their feeding habits differ from the members of such wellknown genera as Zamenis and Spilotes which have already been considered. Among the species of the Coronelline genera under discussion there is some diversity of habits as regards the character of the food. With Coronella some of the species evince a preference for lizards, while also subsisting upon small mammals; with others the habits are quite reversed. All of the species are more or less cannibalistic. With the New World genus Ophibolus, the cannibalistic tendency is particularly marked and carries with it a ferocity that impels the reptile to attack and kill other serpents of a considerably larger size than the aggressor. The Ophibolus getulus, common King Snake, feeds largely upon other snakes, attacks and kills the poisonous species and is immune to their bites, unless the fangs pierce an important organ. This immunity is generally indicated among the markedly cannibalistic snakes. The smaller species of Ophibolus are cannibalistic, but also feed frequently upon mice and young rats; those inhabiting the southern latitudes varying the diet with lizards. All may be rated as of economic value. The species of Rhinochilus are of similar habits. The immediately related and single species of Cemophora of the southeastern United States, feeds upon other small snakes, lizards and raids the nests of small rodents to prey upon the young. The writer has noted the habit of this snake of eating the eggs of lizards that are deposited under the loose bark of decaying trees, the species principally preyed upon being Eumeces quinquelineatus and Lygosoma laterale. A female, Cemophora coccinea in the writer's possession displayed the unusual trait of depositing a batch of eggs under a flat stone and a few days later devouring her entire litter.

In a series of Colubrine genera composed of small species, it is of interest to mention the food of the members of Cyclophis and Liopeltis. These are green, or bronze-green species inhabiting the 


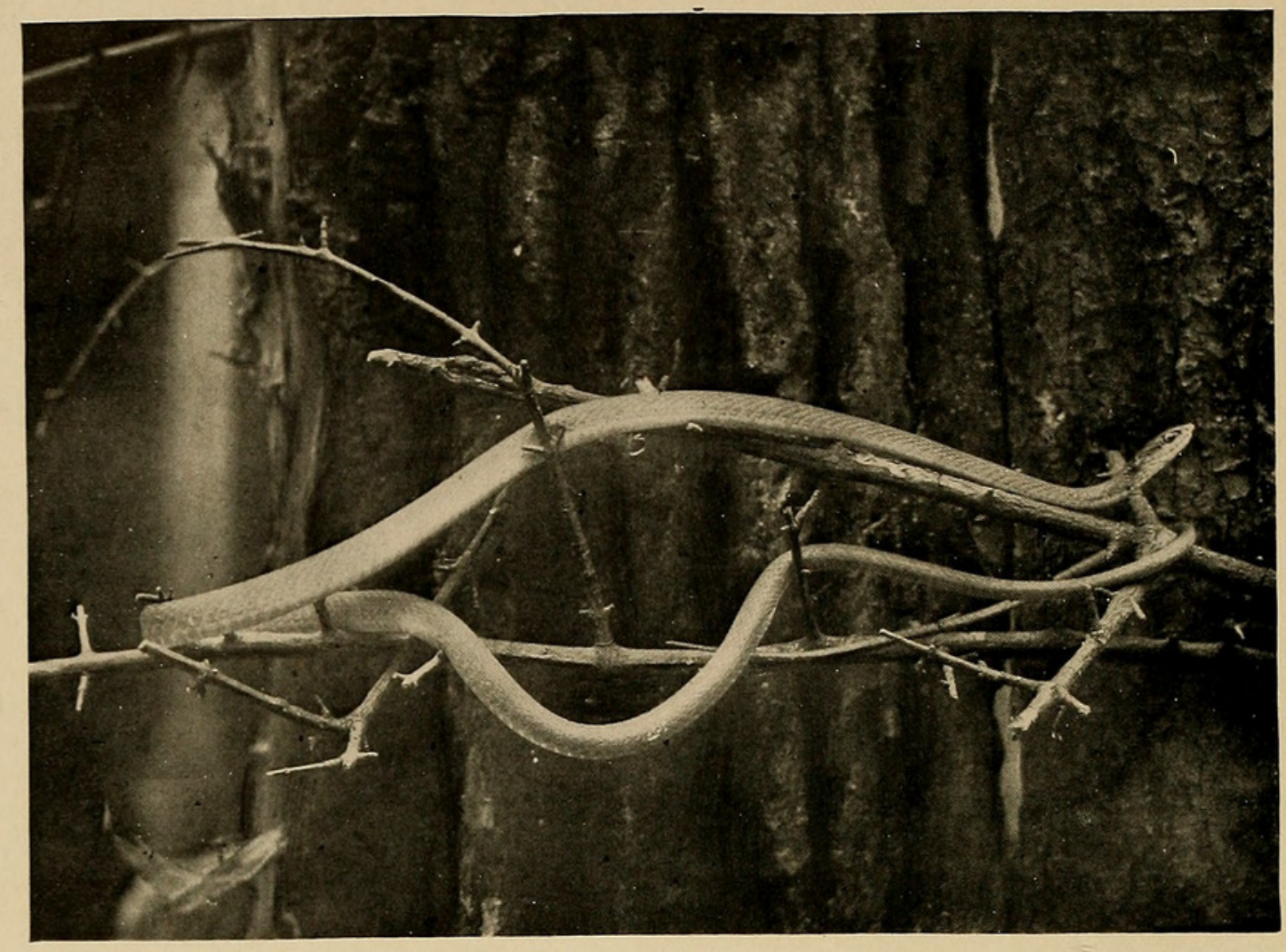

FIG. 92 GREEN SNAKE, Cyclophis aestivus

Insectivorous. Few snakes exhibit similar feeding habits

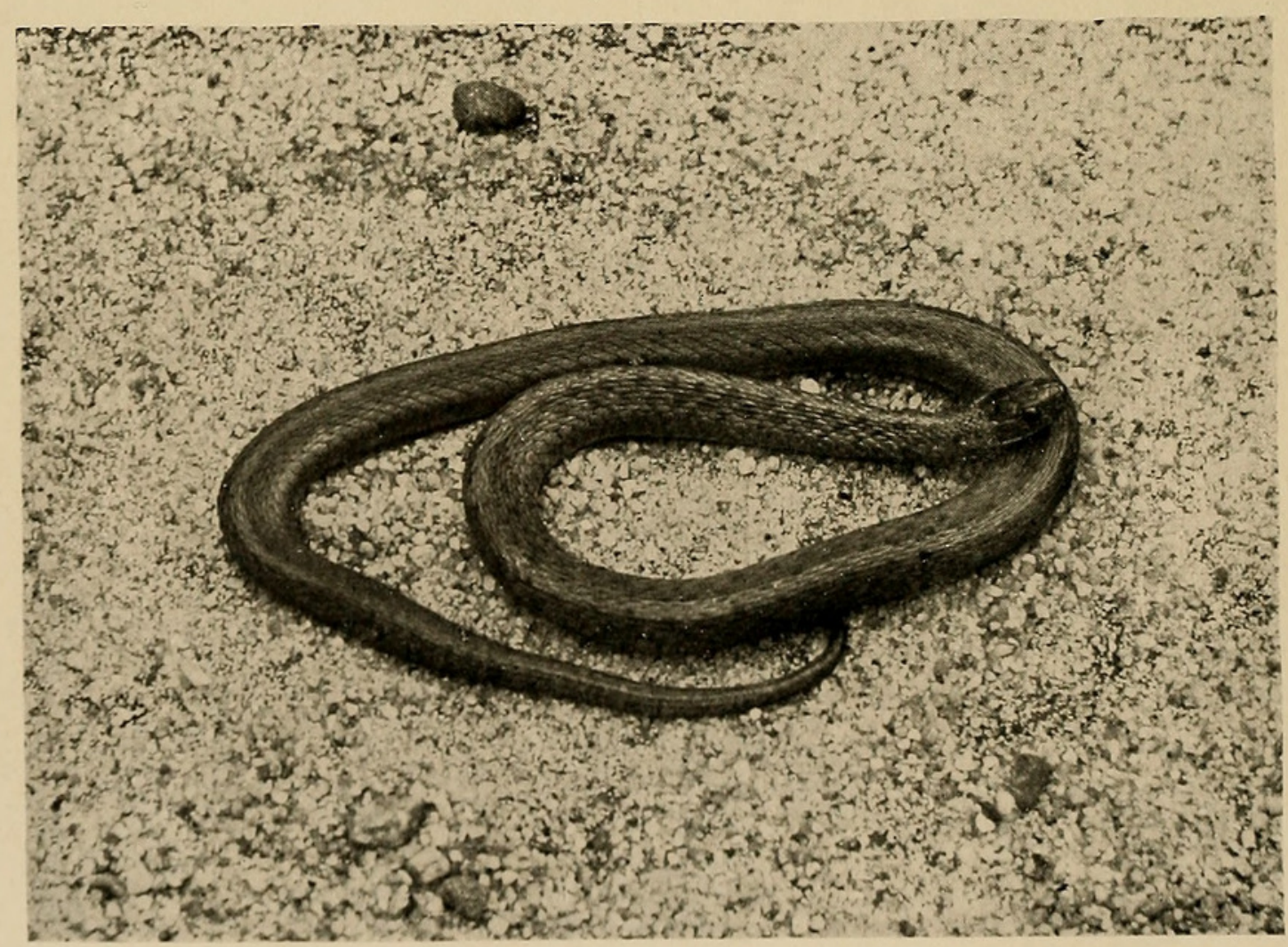

FIG. 93. DE KAY'S SNAKE, Storeria dekayi

Unusual in restricting the food to earthworms and the larvae of small beetles 
United States and Asia. Two common species, both of a brilliant green, inhabit the United States. The species of these genera are particularly interesting owing to their insectivorous habits. From his observations of small species of snakes and dissections of numerous preserved specimens, the writer is not inclined to believe that many snakes feed upon the imagoes of insects, though it is probable that a number of the very small, secretive species not infrequently devour the larval forms of coleopterous insects. With Cyclophis and Liopeltis, the species feed generously upon the imagoes of various insects. These snakes are most frequently to be found among low bushes and in vines; but they occasionally prowl in stone piles. They feed upon orthopterous insects, grasshoppers and crickets, and the writer has found the remains of beetles in the stomachs of preserved examples. All of the species are particularly fond of the hairless larvæ of the noctuid and geometrid moths, and a considerable number of dissected specimens showed these reptiles to often feed upon spiders. Long observation has demonstrated, strangely enough, that they will not eat earthworms, the partial food of a great number of the smaller serpents. The species of Cyclophis will eat small lizards.

Abastor and Farancia, both genera of rather doubtful relationship, though immediately allied to one another, are each composed of a single large and handsome species inhabiting the low coastal region of the southeastern portion of the United States. Both species are burrowers and from their substantial build would appear to subsist upon frogs and toads. Repeated experiments with a great series of adult examples of both species have resulted in inducing these reptiles to partake of but one type of food and under a single, unvarying condition, when these reptiles freely feed. The provision described involves the provision of a shallow tank, well stocked with frog tadpoles. The method of capturing the prey resembles that of the water snakes, although representatives of the species could not be induced to take fish. Very young specimens of Abastor erythrogrammus feed upon earthworms, but this food appears to be discontinued when the snake is a few months old. The members of both genera are oviparous; the eggs requiring about eight months for incubation.

Subfamily Rhaciodontinae: The single species, Dasypeltis scabra, of Africa is characterized by the extreme modification of the teeth which are much reduced in number and the presence of sharp edges of several of the vertebrae extending into the æsophagus. This highly specialized structure is employed in cutting the shells of 
the eggs of birds, sometimes of reptiles, upon which the serpent appears to wholly feed. After the covering of an egg is broken the contents are permitted to flow down the serpent's throat, and the fragments of shell afterwards disgorged. This snake appears to be quite unique among members of the entire order in subsisting entirely upon eggs; also in its habit of voluntarily disgorging useless remnants of its food.

The Opisthoglypha: The serpents of this division appear to represent the early types of poisonous snakes. Specialization has progressed to a point where venom-injecting teeth are evident, though of a crude type. Their furrowed fangs are of invaluable assistance in subduing the prey and are manipulated with great ingenuity. Owing to the fangs being situated posteriorly, these snakes are unable to strike and thus wound the prey, which is always tenaciously gripped with imbedded fangs and held until it is overcome by the poison. With the different method of feeding, there is a difference in the food as compared with other poisonous Colubrines - the Proteroglypha. The great majority of the Opisthoglypha feed upon cold-blooded creatures, reptiles, amphibians, fishes and various invertebrates. This is necessarily the case with a great number of species, owing to the very short fangs which would be unable to pierce the pelage or feathers of small mammels or birds, or efficiently inject the poison. The simple fang mechanism of these serpents is primarily intended to be employed in the subjugation of creatures with comparatively naked skins, under which head must be included a favorite food of many of the terrestrial and aboreal species - the lizards-the scales of which are readily pierced by the strong, sharp fangs. With some genera, like the South American Tomodon, the fangs are greatly elongated and advanced to a position nearly under the eyes. This dentition would be effective upon small birds and mammals, but unfortunately, the writer has been unable to obtain examples for observation.

The Homalopsinae: This subfamily of the Opisthoglypha has become specialized in assuming strictly aquatic habits and is thus analagous to the Hydrophiinae of the Proteroglypha although the members of the latter evince the more extreme specialization along these habits in taking to the sea. With this specialization of habits comes the necessary and characteristic diet of fishes. The members of the Homalopsinae feed also upon batrachians, although fishes form the greater part of their diet. Fishes with the fins terminating in 
long and sharp spines are a common prey but are swallowed without difficulty as the snake's venom renders the muscles quite inert. The quarry is swallowed head first, the bristling spines folding against the body while deglutition goes on.

The Dipsadormorphinae: Despite the elaborate array of species of this subfamily, it is difficult to obtain a representative series of living examples for study. Many of the species are small and secretive; others are arboreal and difficult to capture, and amid these conditions they escape the attention of the collector of living reptiles. A number of living examples of the Dipsas type, such as Tarbophis, Trimorphodon, Lycognathus, Dipsadomorphus, Himantodes and Sibon have been under the writer's observation. All the specimens studied were oviparous and showed a preference for small, soft-scaled lizards and batrachians; usually feeding at night. With Tarbophis and Trimorphodon, lizards are preferred. The specimens of Lycognathus, Dipsadomorphus and Himantodes preferred small frogs. Examples of Tarbophis and Lycognathus were induced to take very young mice and birds, but these were refused if even thinly clad with pelage or feathers. With the strictly arboreal genera, such as Dryophis and Oxybellis there is an unvarying preference for lizards. No specimen of these latter genera was noted to feed upon batrachians, and but occasional examples exhibited any interest in freshly caught birds or small rodents from the nest.

\section{FOOD OF THE PROTEROGLYPHA}

While there is marked specialization among the snakes of this series in the possession of venom-conducting teeth, placed anteriorly, and temporal glands for the copious storage of what appears to be the most deadly of the venoms existing among all the known types of poisonous reptiles, the character of the food seems to be analagous to that of the Aglypha-the wholly non-venomous Colubrine forms. However, in making up a general average of the species of the Proteroglypha observed alive, the number showing a preference for warmblooded prey is slightly in excess over those feeding upon other reptiles or batrachians. One peculiarity may here be noted. The writer has had under observation no serpent of this series that indicated a tendency to feed exclusively upon warm-blooded prey-a trait already noted among several genera of the Colubrinae. 
Subfamily Hydrophiinae: The food of the reptiles that have taken to a marine life, consists of fish, crustaceans and various other types of salt-water invertebrates. Very few examples that have been observed in captivity have been induced to feed, and small fish were taken. Wild specimens have been noted feeding upon fish which were quickly subdued by the poison. Owing to the roving disposition of these serpents, demanding more activity than displayed by terrestrial snakes, they undoubtedly feed at quite frequent intervals.

Subfamily Elapinae: Unlike the subfamilies of the Aglypha and Opisthoglypha, the genera of the Elapinae evince little tendency for arrangement into groups from the standpoint of relationship and well-defined selection of food. At least one genus, however, exhibits food selection of marked interest. This is the single New World genus of the subfamily-Elaps. The writer has had abundant living material for study for an extended period of years. All of these snakes are cannibalistic and absolutely restrict the food to other species of snakes and lizards.

Of the Elapinae of the Australian fauna, Pseudechis, Diemenia and Brachyaspis prefer small mammals and birds to other food, although they occasionally eat lizards. None could be coaxed to take batrachians which appeared quite foreign to their diet. Of the African species studied, the Ringhals, Sepedon haemachates and three species of Naja were of similar habits.

The Indo-Malayan cobras, Naja tripudians and N. bungarus (King Cobra) exhibit food habits of great contrast. The common cobra feeds ravenously upon small mammals and birds and lives for years in captivity. It will also eat birds' eggs, but instead of breaking the shells in the throat by muscular contraction as is the habit of most colubrine serpents* when thus feeding, the eggs are swallowed entire and the shells left to be broken by the action of the gastric juices, which process is completed in about forty-eight hours. The writer has never observed an example of the Indian Cobra feeding upon either reptiles or batrachians, and it is his belief that this species limits its food to warm-blooded creatures. Compared with the feeding habits of the Indian Cobra, the diet of the King Cobra, Naja bungarus, is of particular interest, as this nearly allied, much larger and powerful snake is strictly cannibalistic. It appears never

*A habit commonly displayed by Coluber, Pituophis and allied genera. 
to feed upon mammals or birds, and of particular significance is the evident restriction of the diet to snakes alone. The writer's srecimens have lived for years with various lizards running about their cages, without eliciting the least interest on the part of the Cobra. Moreover, the writer's experiments tend to show that other poisonous snakes are seldom or never eaten. These habits are at variance with other markedly cannibalistic Elapines, as the species of Elaps have been noted to kill and eat small rattlesnakes, Sistrurus, while they often feed upon the smaller lizards of the Scincidae and Iguanid.ae

Following are notes involving the feeding of Naja bungarus:

To test the assertion that $N$. bungarus feeds but seldom upon the Viperine snakes, possibly possessing an instinctive dread of the deep wounds liable to be inflicted by the fangs of such reptiles, the following experiment was conducted.

A large, thick-bodied, harmless water snake (Tropidonotus taxispilotus), and a poisonous water moccasin (Ancistrcdon piscivorus), of much the same proportions, were selected for the experiment during a period when the big cobra was voraciously awaiting its weekly meal of a living snake. The door of the cage was rolled back, and the poisonous snake thrown inside. The cobra made the customary rush for the food, but upon reaching the snake paused abruptly.

This was the first time in the feeding of this king cobra in our Reptile House that he failed to immediately seize his victim and begin to swallow it. The moccasin was permitted to remain in the cage for about five minutes, during which time the cobra reared slightly from the door, and regarded it intently. To ascertain whether the cobra was hungry, a common striped snake was placed in the cage. It was grasped and swallowed without hesitation.

The moccasin was again introduced. There was the same rush, and the same careful examination of the newcomer. This time, annoyed by the unceremonious treatment it had received, the pitviper showed fight. Upon this display of hostility the cobra backed off hurriedly, nervously dilating its hood, and rearing upward. The moccasin was finally removed unharmed, and the large, harmless water snake was quietly placed in the cage. To the human observer it matched the moccasin closely, and made a show of temper considerably more emphatic than the former, but the cobra attacked it without an instant's hesitation and soon swallowed it. This experi- 
ment was repeated, and always with the same result. The cobra appeared to instantly distinguish the dangerous character of the poisonous snake.

Of all species of snakes under the writer's observation, the king cobra is the most intelligent. Its actions indicate quick reasoning. A slight movement at the door of its cage will bring it rushing to the opening, where it prowls about, nosing and inserting its tongue along the frame, in the anticipation of food. This snake has been frequently observed, as the feeding period was approaching, to assume the graceful attitude of its kind-head and neck upraised to the level of the small plate-glass window in the door of its cage-and follow intently, with turning head, the movements of the keepers in the passage behind the cages.

In serpents, such actions are unusual. They appeal more to mental faculties exhibited by mammals. In numerous other instances the writer and his keepers have noted the unusual intelligence of king cobras. Their apparent sagacity, together with the possession of fangs, and probably the most virulent poison of all snakes demands the greatest caution on the part of those who maintain a collection of living specimens. While feeding, the king cobra not only displays considerable cunning, but also great agility. When a snake is placed in the cage, the cobra dashes upon it, seizes it by the middle of the body, and within a few seconds' time the fangs have done their work. Snakes, however, are rather slow to succumb to the venom of these reptiles. On the part of the victim there is vigorous opposition to being thus treated. The cobra is repeatedly bitten, but it regards with stoical indifference the superficial wounds inflicted by the teeth of its prey, and continues working the body of the snake along in its jaws with the idea of reaching the head, which portion is swallowed first. Sometimes the quarry is seized near the head, and in such cases it soon disappears down the cobra's throat. Frequently however, the cobra has some trouble in working its jaws toward the victim's head. At such times the larger reptile pauses often, and awaits an opportunity of seizing the other by the neck. If the attacked snake makes a movement to bite the cobra on head or neck, there is a counter movement of great rapidity. The body is released and the approaching head is seized with astonishing quickness, after which performance the engulfing process begins without more ado.

The fine representative of this species in the Reptile House has no aversion to taking snakes that have been freshly killed. Its good- 
nature permits economy to be practiced, for in times of scarcity each snake offered is first killed and stuffed to its full capacity with frogs or rats, and thus it is made to equal in bulk and nourishment a half dozen snakes of equal length not treated in this manner.

Several examples of Naja, representing $N$. bungarus, $N$. tripudians and the African $N$. haje have been received at the Reptile House, where examination showed they had been deprived of their fangs by native snake charmers. After such mutilation few poisonous snakes can be induced to feed. Reptiles in th s condition have been kept alive and in vigorous condition, however, by force-feeding them with beaten eggs poured down the throat through a glass funnel after the snake has been grasped by the neck and the body held upright.

The food of Elaps, the only New World genus of the Elapine serpents has already been noted to consist entirely of other snakes and lizards. The method of feeding is similar to that of the king cobra, though these smaller snakes dipslay less ingenuity in overpowering their prey. It is quickly grasped and worked along in the jaws until the head points down the throat, when swallowing commences. Upon cold-blooded prey the poison is slow in taking effect; and, although the fangs may be observed to be repeatedly and vigorously employed, the subtle fluid appears to aid the snake but little in subduing the quarry, which generally struggles energetically during the entire swallowing process.

These snakes will consume serpents of surprising dimensions in proportion to their own length and thickness of body. The writer has observed the Harlequin Snake ( $E$. fulvius) swallowing snakes that were but a few inches shorter than the feeding reptile, and of greater circumference of body. After completing a meal of such proportions, the gorged snake is rendered so rigid of body that it is unable to coil properly, and the skin is so greatly distended that the scales appear as well-separated rows of dots.

All of the species evince a liking for lizards, and especially the smooth-scaled species of the Family Scincidae. Numerous captive examples of the Harlequin Snake have fed upon the blue-tailed lizard (Eumeces quinquelineatus), while specimens of the large South American Coral Snake ( $E$. corallinus) have taken adult specimens of the red-headed lizard (Eumeces quinquelineatus erythrocephalus) fully nine inches in length, and of stout proportions. The lizards show much more susceptibility to the action of the poison than snakes. 
The writer has had no opportunity to study living examples of the Amblycephalidae. Systematic observations may reveal interesting traits among these snakes, characterized by the small gape and limited dilatability of the swallowing mechanism. Apparently connecting the Colubridae with the Viperidae, their methods of feeding and the kind of food selected are characters which should be noted together with their alleged relationship.

The Viperine Snakes: Among these, the most highly specialized forms of reptile life we find what appear to be indications of welldefined food selection following the trend of specializa on. Although there is an immediate relationship between New and Old World species of the Crotalinae, the writer believes there should be generic distinction between the New and Old World species of Ancistrodon and Lachesis. He bases this opinion upon preliminary studies of his friend Dr. Joseph E. Tompson, who explains that the hemipenial characters of the species of the Eastern Hemisphere are markedly different from the New World Crotaline snakes under the same generic rating. From the standpoint of relationship and food the New World Crotalinae may be thus defined:

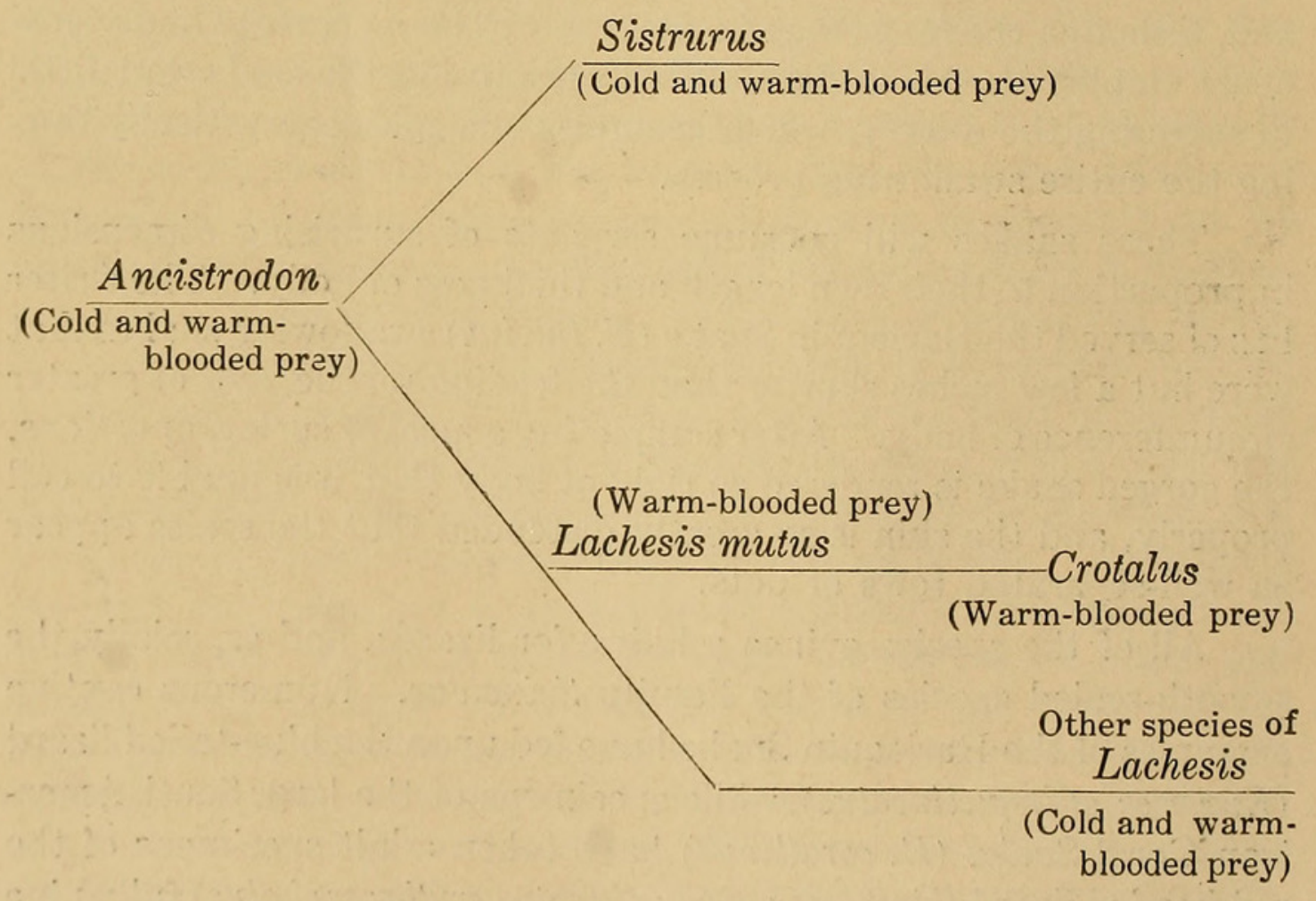

The species of Ancistrodon, apparently representing an older type of development, possess relatively short fangs. Unlike the more 


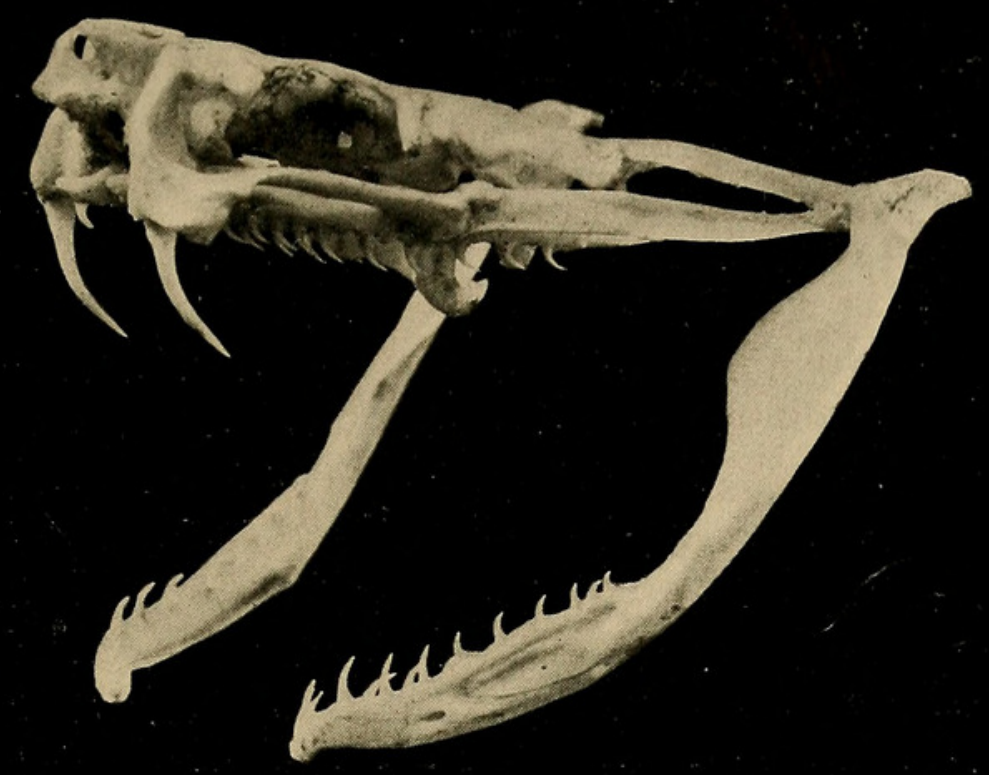

FIG. 94. SKULL OF MOCCASIN, Ancistrodon piscivorus

The dentition points to the earlier types of Crotaline snakes

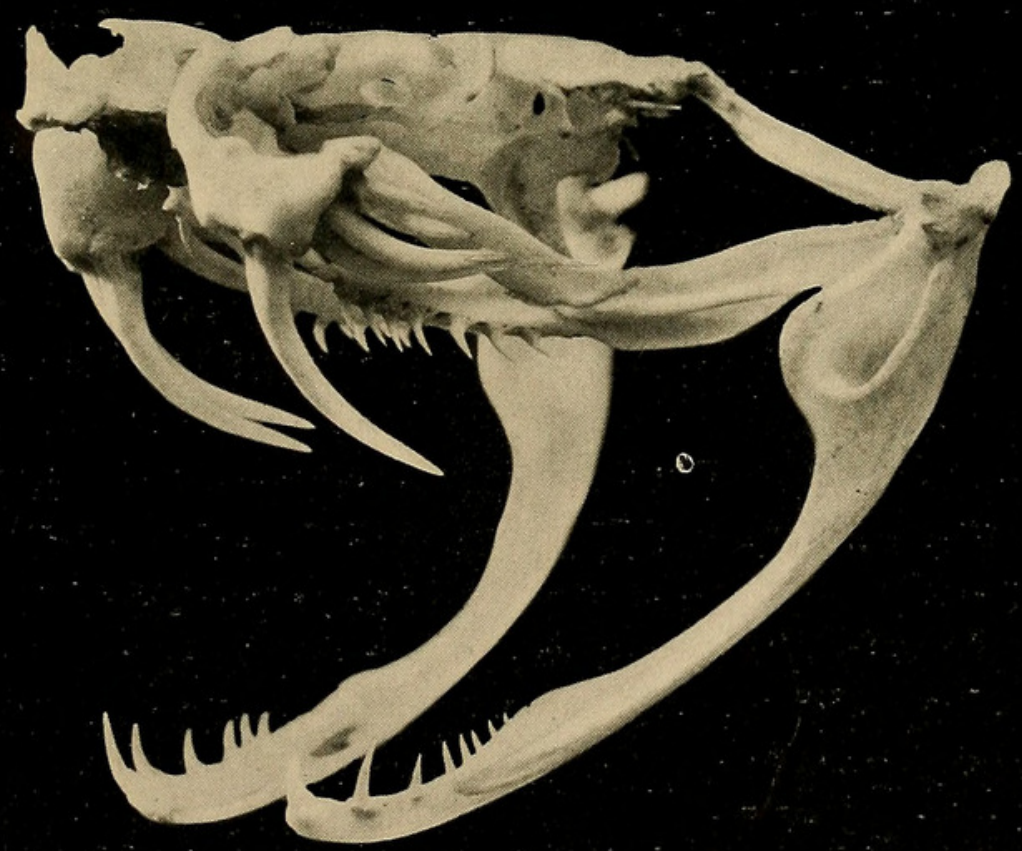

FIG. 95. SKULL OF BUSHMASTER, Lachesis mutus

Extreme specialization in fang-development is to be noted 
highly specialized Viperine snakes, they seize their prey and retain the hold until its death. All of them are omni-carnivorous, feeding upon mammals, birds, reptiles, batrachians and fish. The writer has observed none of the species - not even very young examples of anyto show interest in earthworms or like food; the food appears to be quite restricted to forms of vertebrate life, the latter a condition noted with all the observed species of the Viperidae. This broad range of food renders Ancistrodon characteristic among all viperine serpents. The food habits of Sistrurus appear significant when compared with structural characters similar to Ancistrodon. The writer believes Sistrurus to be a direct offshoot of Ancistrodon and on an independent branch of development from the larger and more highly specialized rattlesnakes, Crotalus. The species of Sistrurus feed as readily upon frogs as they do upon small mammals and birds. A peculiar trait is the disposition to retain the hold upon cold-blooded prey while they strike warm-blooded creatures. We thus note two habits in their feeding - that of the more primitive long-fanged snake and of the highly specialized type. The same feeding habits are to be noted among the New World species of Lachesis-except L. mutus. Snakes of the $L$. lanceolatus, alternatus and neuwiedii type feed upon mammals, birds and batrachians, and are inclined when nervous, to merely strike the warm-blooded food while the cold-blooded prey is seized and held until dead or swallowed while it is alive. Lachesis mutus is an exception. The writer is not at all convinced as to the correctness of including this unique form under the same generic heading of the snakes formerly grouped under Trigonocephalus. Its source of origin has apparently kranched abruptly away frcm that group and represents the origin of Crotalus, with the immediately related South American $C$. durissus and the geographical extension and elaboration of species toward and into North America. From repeated examinations of the intestinal contents of exampies of Lachesis mutus, it seems to feed altogether upon warm-blooded prey. Adult captive examples cannot be induced to take food; Mr. R. R. Mole, of Port-of-Spain incluced a young example to take mice. With the reasonable certainty that this fine reptile, by far the largest of all Crotaline serpents confines its food to warm-blooded prey, we have a habit rendering it unique among the species of the genus it stands as a member. These feeding habits also tally with those of Crotalus; no example of any of the species of which has been noted by the writer to feed upon other than warm-blooded prey. The writer's notes on 
the genus Crotalus cover observations on living representatives of twelve species.

In the Old World, the Ancistrodon type has survived in the shape of puny terrestrial forms, while the Lachesis (Trimeresurus) types have become an extensive branch of mostly arboreal forms; among all of them we find the food selection to cover cold-blooded prey as well as small mammals and birds.

The Viperinae: It is not apparent that this present subfamily of the Viperinae, originating along a source involving the Crotalinae, but represents a parallel type of development from a near source. In lesser specialized forms, like Causus, appealing to the Colubridae in scalation of the head and quite remarkable in being oviparous, we note an arbitrary habit as compared with the later forms in the food selection of cold-blooded prey, although these snakes also feed upon small mammals. Among the smaller species of Vipera, with the larger head shields such as $V$. berus, there is a tendency to feed upon lizards besides small mammals. Coming to the highly specialized forms like Bitis and Atheris, we note the same positive restriction of food to warm-blooded prey as described to exist among the later Crotalines.

As a comparative review of the food selection of serpents, the writer has prepared a table that follows and which includes only those species under thorough observation and represented by a generous number of examples. The term omni-carnivorous is used to concisely designate those species which feed upon both warm and cold-blooded prey. Species of pronounced economic value are marked.*

\section{CHARACTER OF FOOD**}

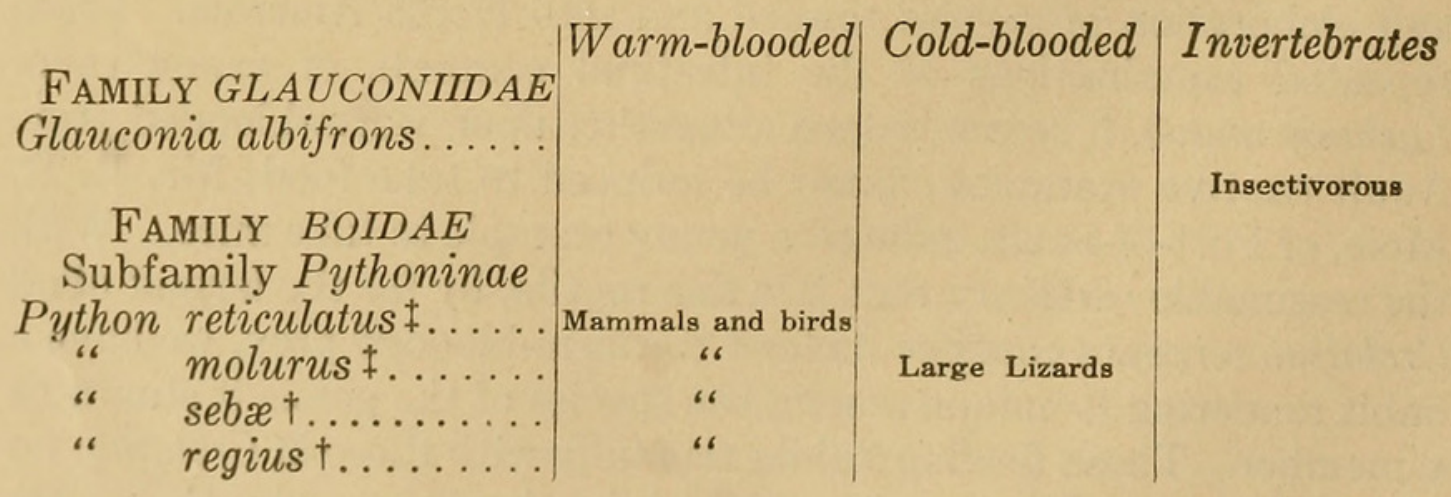

**See reference notes at end of schedule. 


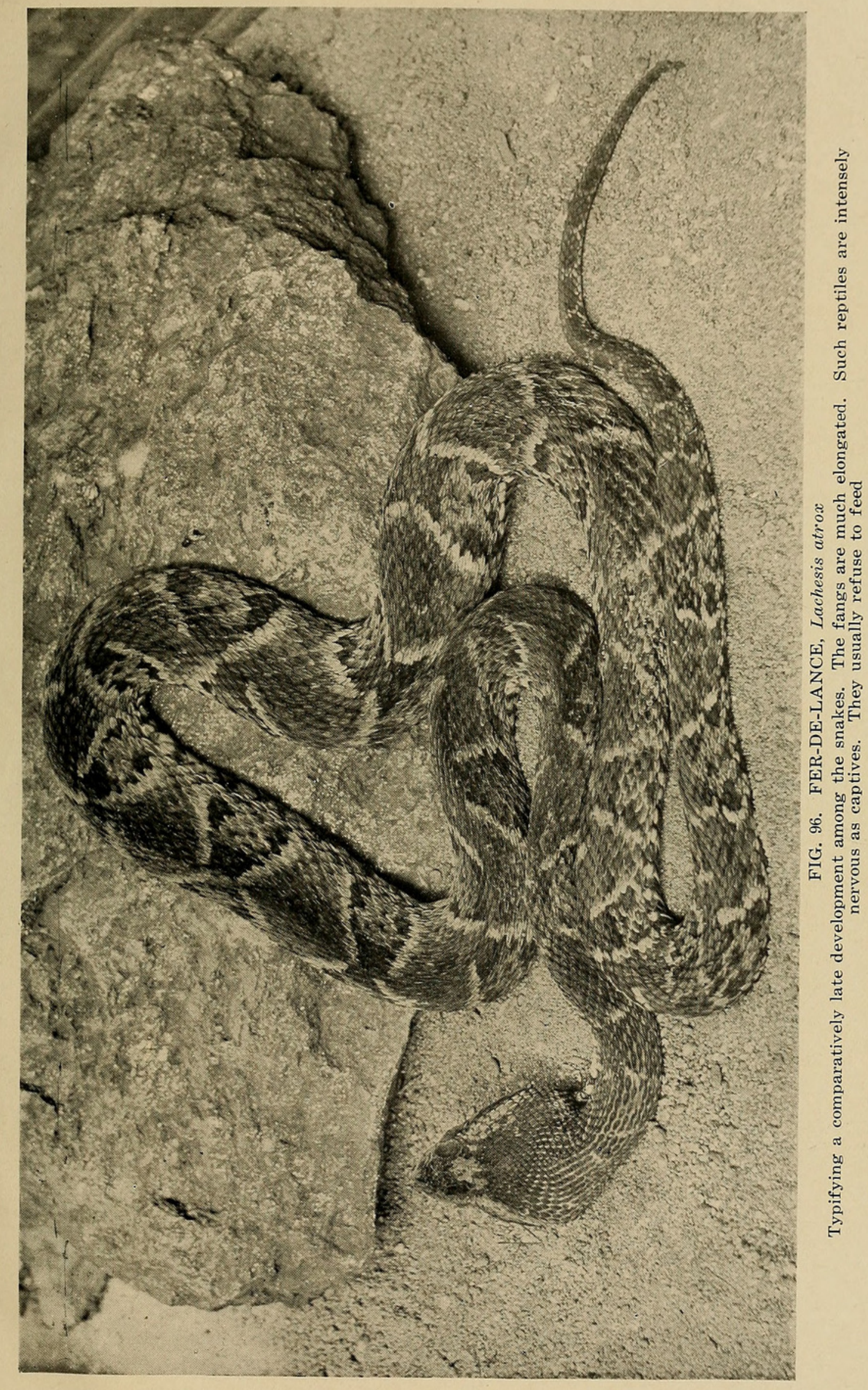




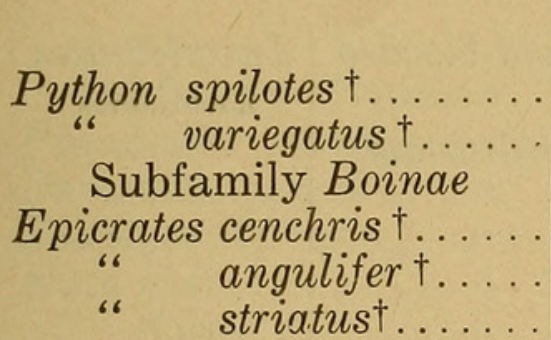

Corallus madagascariensis

" cookii ††.......

" hortulanum $\dagger$ ".

Eunectes murinus ${ }^{\dagger} . . . .$.

$$
\text { " notæust. }
$$

Ery conicustt† " radix.........

\section{Warm-blooded Cold-blooded}

Invertebrates

Large Lizards
Boa constrictor $\dagger$

" imperatort.

" mexicanus ${ }^{\prime}$

" madagascariensist.

" johnii †t†

" jaculusttt.

Charina bottætt

FAMILY COLUBRIDAE Subfamily Colubrinae Eutaenia sackenii...... " saurita......... " proxima...... " butleri........

" sirtalis.

" elegans

" e. infernalis

" " marciana.

" "vagrans

Tropidonotus leberis.
Small mammals
66

6

66

Lizards

66

66

66

Batrachians;§ fishes

6

66

tessellatus.

Seminatrix pygxa.......

Helicops angulatus...... Tropidoclonium lineatum. Clonophis kirtlandi...... Storeria dekayi.........

" occipitomaculata.
66

66

68

66

66

66

66

66

66

66

66

66

66

66

o6

Earthworms

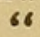

66

66

66

o6

66

Crustaceans

66

6

ac

66

Earthworms

Salamanders

Batrachians; fishes

66

Earthworms 


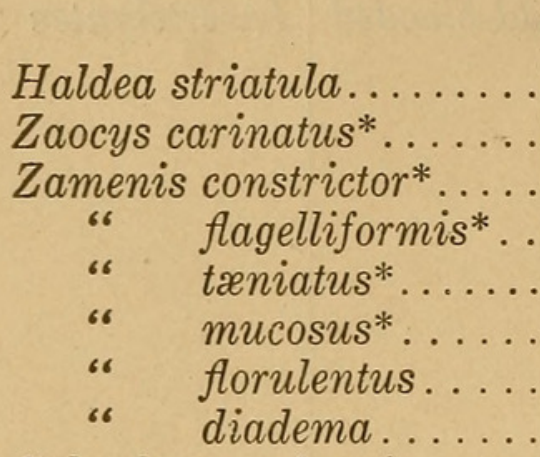

Salvadora grahamix Drymobius margaritiferus Spilotes corais*........ variabilis

Coluber guttatus*...

" subocularis*.

“ quatuorlineatus*.

“ vulpinus*......

66 obsoletus*...

Pituophis melanoleucus* " sayi*.......

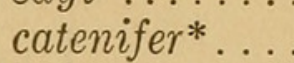

Leptophis liocerus ...... Dromicus angulifer..... Heterodon platyrhinus. . " simus....... Coronella austriaca...... Rhinochilus lecontii..... " antonii

Cemophora coccinea..... Virginia valeriæ........ " elegans......... Abastor erythrogrammus. Farancia abacura. Carphophis amœnus.....

Subfamily Dipsadormorphinae Tarbophis fallax....... Trimorphodon lyrophanes Himantodes cenchoa..... Leptodira annulata..... . Dryophis prasinus...... mycterizans... Oxybelis acuminatus.....

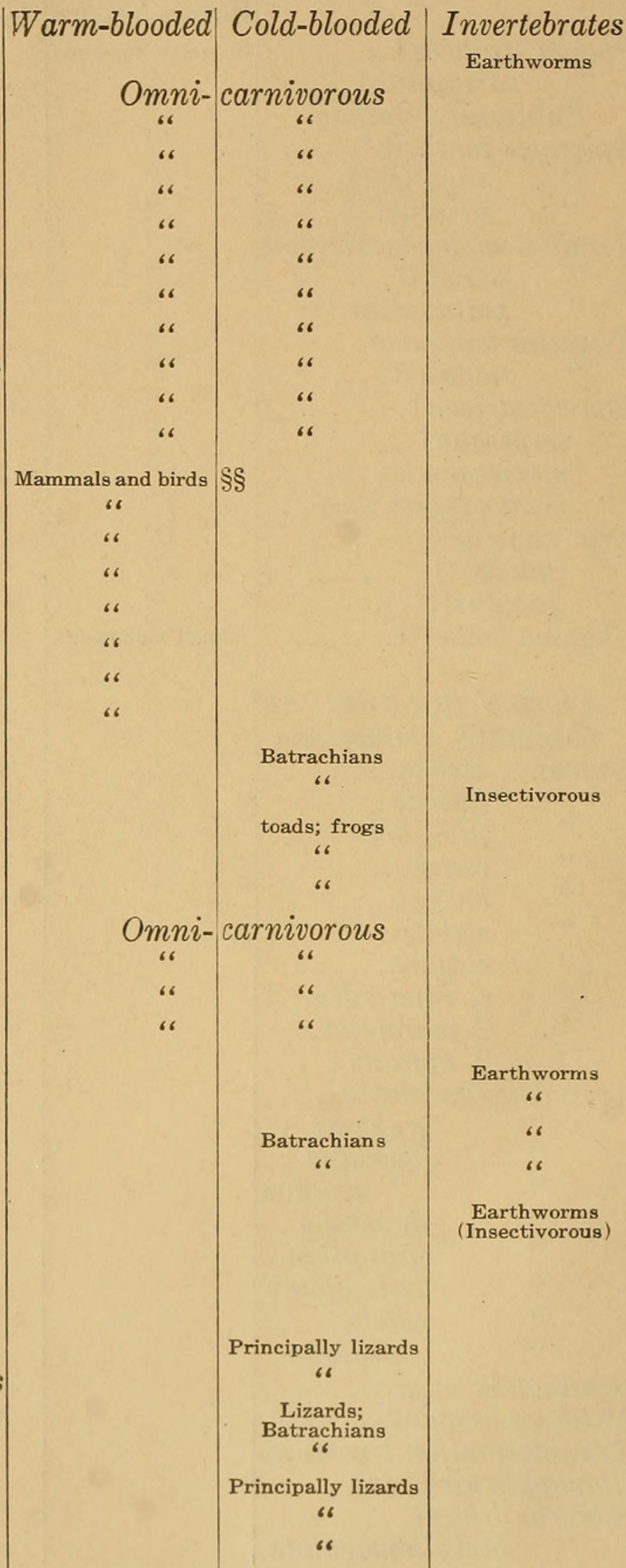




\section{Subfamily Elapinae}

Pseudechis porphyriacus

Denisonia superba.

Brachyaspis curta......

Naia haie.

" flava.

"

" melanoleuca......

" tripudians........

66

bungarus..........

Sepedon hæmachates....

Elaps corallinus........

" fulvius..........

FAMILY VIPERIDAE Subfamily Viperinae

Causus rhombeatus.....

Vipera berus.

"aspis.

66

66

ammodytes.

russellii.

Bitis arietans

"gabonica.

“ nasicornis.

Cerastes cornutus.

" vipera.

Subfamily Crotalinae

Ancistrodon piscivorus.

Lachesis mutus. contortrix..

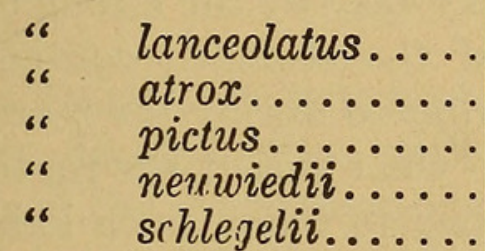

Sisturus miliarius.

" catenatus.

Crotalus terrificusşsฐ...

" confluentus.....

" durissus........

" horridus.........

of

\section{Warm-blooded |Cold-blooded | Invertebratas}

Mammals and birds

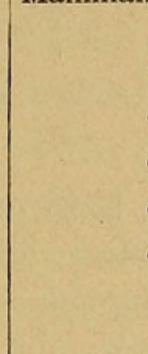

Mammals and birds

Strictly cannibalistic Mammals and birds

“6

16

Small mammals Lizards

Mammals and birds

66

66

86

16

66

66

Mammals

66

\section{Omni-carnivorous}

Never induced to feed in captivity, but known to take mammals in wild state.) $\$ \varsigma \$$

$$
\text { Omni-carnivorous }
$$

\begin{tabular}{c|c|}
66 & 6 \\
68 & 16 \\
66 & 68 \\
66 & 06 \\
66 & 66 \\
d birds &
\end{tabular}




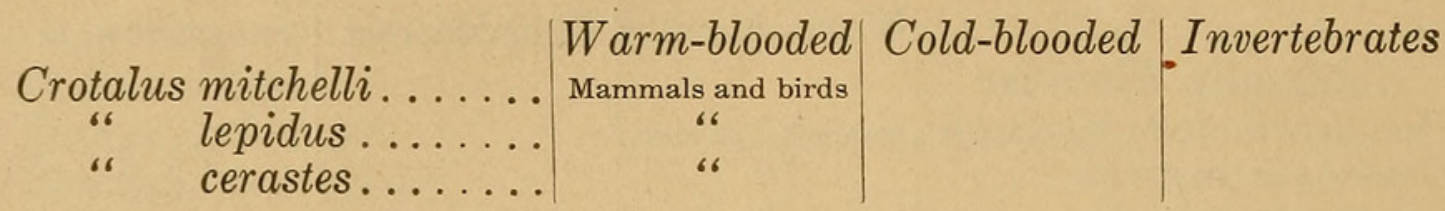

\section{NOTES:}

$\ddagger$ In captivity these species take swine, large rodents and poultry.

†Prefer large rodents (principally rabbits), chickens and pigeons.

$\dagger \dagger$ As captives, take sparrows, young pigeons and young rats.

†† Captive examples are fed upon sparrows and mice.

§Frogs, toads, tadpoles, salamanders and various small fresh water fish.

§§Mice and rats; sparrows. Particularly hardy in captivity.

$\S \S \S$ Mature captive examples have never been induced to take food. The only feeding note concerning a captive specimen comes from Mr. R. R. Mole, of Port-of-Spain. A young example under his observation took mice.

$\S \S \S \S$ Captive rattlesnakes prefer rodents and small birds. The smaller species in the New York Zoological Park are fed mice, young rats and sparrows. Such species as $C$. adamanteus and $C$. atrox are given young rabbits and cavies.

While reptiles have received their full share of technical attention, very little practical work has been done relating to investigations of their economic importance. The preceding summary of species studied alive will point out a considerable number that may well merit the field observations of the planter and general agriculturist. Members of such genera as Zamenis, Coluber, Pituophis and Ophibolus may be regarded as of marked economic value in the vast grain belts of the United States and their introduction into localities infested with the smaller sciurine rodents is well worth serious trial and extended observation. The species of Pituophis should be particularly useful owing to their strictly terrestrial habits and inclination to prowl into the burrows of small mammals. With a liberal number of snakes introduced into a rodent infested territory, investigations of the reptiles' food is comparat vely easy by the killing of a moderate number and the examination of the stomach contents. These observations should be carefully conducted during the rearing season of mammalian pests to determine to what extent the reptiles prey upon the young in the nest. If inclined to follow such habits they must be rated of high economic importance. While a number of the omni-carnivorous Colubrine species feed upon birds, their depredations among these in a region abounding with rodents would be small as they would naturally select the more easily captured prey. As captives the greater number. of such snakes are voraciously fond of rodents - particularly of the young. 


\section{Feeding Traits of Serpents}

Various curious feeding traits exist among serpents, which may be characteristic of individual species or of all the members of a genus. The reluctance of some species to feed at all as captives has already been described. This particularly relates to species of the Viperidae. Exceptions to this habit are found among the species of Ancistrodon which readily feed, even under adverse conditions. A general habit among all serpents is the abrupt and entire cessation of feeding with the female as pregnancy develops. This relates to both oviparous and viviparous species. With the former, there is a shorter period of fasting, this lasting about four weeks. With the viviparous species there is a period of positive fasting, varying among serpents of different groups from six to eight weeks. Theoretically it would appear that excess nourishment would be needed during the period of the development of the young, but exceptions to this rule, which feed occasionally up to the deposit of eggs or birth of the litter, are rare. The period of gestation among the viviparous Colubridae is about eighteen weeks; among the Viperidae it appears to be about twenty weeks. With the Boidae, gestation seems to require a longer period. The writer has usually noted the viviparous members of the Boidae to commence their fast three months before the appearance of the young. Oviparous species that have been received while containing eggs, never fed until the eggs were deposited.

In the assimilation of its food, the snake, if in healthy condition, wholly dissolves the bones, and usually the teeth. Strangely enough, the claws of a mammal do not appear to be generally attacked by the reptile's gastric juices. The pelage of a mammal is little affected by these juices, and masses of it when dried and separated from the excreta so retain the color and lustre as to render identification possible.

During the action of digestion on the great mass of unlacerated prey, decomposition with its attendant gases, is rapid, and the stomach of the reptile becomes greatly distended until the gastric juices break through the body walls of the engulfed animal. Poisonous snakes appear to more quickly assimilate prey dying from their venoms than if it be killed in other ways.

A great number of serpents can be induced to take freshly killed animals. With most specimens of this type it is necessary to move dead animals in order to attract the snake's attention. The 
power of scent combined with the mysterious, yet all important, nerve-permeated tongue, are important requisites in locating the food while the reptile is in a wild state. 


\section{$2 \mathrm{BHL}$ Biodiversity Heritage Library}

Ditmars, Raymond Lee. 1912. "The feeding habits of serpents." Zoologica: scientific contributions of the New York Zoological Society 1(11), 197-238. https://doi.org/10.5962/p.206595.

View This Item Online: $\underline{\text { https://www.biodiversitylibrary.org/item/97326 }}$

DOI: https://doi.org/10.5962/p.206595

Permalink: https://www.biodiversitylibrary.org/partpdf/206595

\section{Holding Institution}

Harvard University, Museum of Comparative Zoology, Ernst Mayr Library

\section{Sponsored by}

Harvard University, Museum of Comparative Zoology, Ernst Mayr Library

\section{Copyright \& Reuse}

Copyright Status: Public domain. The BHL considers that this work is no longer under copyright protection.

This document was created from content at the Biodiversity Heritage Library, the world's largest open access digital library for biodiversity literature and archives. Visit BHL at https://www.biodiversitylibrary.org. 